\title{
New insights in the French Guiana continental shelf circulation and its relation to the North Brazil Current retroflection
}

\author{
M. Baklouti, ${ }^{1}$ J.-L. Devenon, ${ }^{2}$ A. Bourret, ${ }^{2}$ J.-M. Froidefond, ${ }^{3}$ J.-F. Ternon, ${ }^{4}$ \\ and J.-L. Fuda ${ }^{5}$ \\ Received 7 February 2006; revised 21 September 2006; accepted 5 October 2006; published 24 February 2007.
}

[1] Moored current measurements carried out from 6 October 2003 to 18 February 2004 over the French Guiana continental shelf are presented. Two contrasted situations have been evidenced in which the currents were either weak and oscillating during the first period (from October to early December) or strong and northwestward during the rest of the survey. Further analysis of these measurements in light of Moderate Resolution Imaging Spectroradiometer satellite images have revealed that these situations are mainly due to the motion of an outer shelf mesoscale feature: the North Brazil Current (NBC) retroflection. Two other main results have also been evidenced in this survey: (1) When the NBC retroflection occurs northwestward of the French Guiana continental shelf, part of the NBC climbs over the shelf slope and propagates to the inner shelf, and (2) the "Guyana current" does not persist throughout the year at a $22 \mathrm{~m}$ depth and below. Finally, the location of the NBC retroflection has also a strong impact on the spread of the Amazon plume over the French Guiana continental shelf and is felt to have an influence on the nutrient supply in this region.

Citation: Baklouti, M., J.-L. Devenon, A. Bourret, J.-M. Froidefond, J.-F. Ternon, and J.-L. Fuda (2007), New insights in the French Guiana continental shelf circulation and its relation to the North Brazil Current retroflection, J. Geophys. Res., 112, C02023, doi:10.1029/2006JC003520.

\section{Introduction}

[2] The recent use of remote sensing techniques with high time and space resolution along with improved oceanographic models have provided new knowledge on the Atlantic ocean circulation pattern along the northern coast of South America. Hence, though the main currents of the mesoscale circulation have been identified for a long time [e.g., Madden and Julian, 1972], their seasonal variability and its consequence on the fate of the Amazon river plume have only recently been understood, yet some important questions still remain unanswered. So far, there is a consensus in literature that the North Brazil Current (NBC) originates from the high-velocity South Equatorial Current (SEC) and flows northwestward along the south American coast [e.g., Stramma and Schott, 1999]. When crossing the equator, a large part of the NBC retroflects and feeds the Equatorial Undercurrent (EUC) which overlaps the lower

\footnotetext{
${ }^{1}$ UMR 6535, Laboratoire d'Océanographie et de Biogéochimie, Institut de Recherche pour le Développement, Campus de Luminy, Marseille, France.

${ }^{2}$ Laboratoire d'Océanographie et de Biogéochimie, Campus de Luminy, Marseille, France.

${ }^{3}$ UMR 5805, Département de Géologie et d'Océanographie, Université Bordeaux I, Talence, France.

${ }^{4}$ UR 109, Institut de Recherche pour le Développement, Centre de Recherche Halieutique Méditerranéenne et Tropicale, Sète, France.

${ }^{5}$ Centre d'Océanologie de Marseille, Marseille, France.

Copyright 2007 by the American Geophysical Union. 0148-0227/07/2006JC003520
}

part of the Tropical Surface Water and the upper part of the Central Water [Stramma and Schott, 1999]. Beyond the equator, the NBC behavior is more controversial in the field's literature. Initially, it was thought to follow a different pattern according to the period of the year: in boreal spring, the NBC was presumed to flow northwestward along the continental slope [Flagg et al., 1986; Richardson and Reverdin, 1987; Schott et al., 1998] toward the Caribbean. During the rest of the year, most of the NBC was believed to separate from the coast and retroflect between 6 and $8^{\circ} \mathrm{N}$ into the North Equatorial Counter Current (NECC) flowing eastward [Johns et al., 1990] while the remnant part of the NBC was thought to feed the so-called "Guyana Current" flowing northwestward along the coast up to the Caribbean [Richardson and Reverdin, 1987; Barnier et al., 2001; Lumpkin and Garzoli, 2005].

[3] Though confirmed by numerical simulations [Barnier et al., 2001], this seasonal pattern of the NBC has been largely debated in recent literature. Thanks to coastal zone color scanner (CZCS) images, Müller-Karger et al. [1988] showed that, from July to December, not a part but the whole NBC was concerned by retroflection. Richardson et al. [1994] solved this discrepancy by suggesting that retroflection eddies (see later) and their northwestward translation could have caused, in boreal fall, the appearance of a continuous current similar to the Guyana Current. Finally, Fratantoni et al. [1995] even wonder if a Guyana Current exists independently of ring passages. 
[4] NBC rings were first observed by Johns et al. [1990] using CZCS imagery, followed among others by Didden and Schott [1993] thanks to satellite altimetry, by Richardson et al. [1994] using lagrangian drifters, by Fratantoni and Glickson [2002] with SeaWIFS ocean color imagery and by Ffield [2005] with SST measurements by Microwave Imager. Simplified theoretical models support the presence of NBC rings as momentum conservation applied to the NBC retroflection necessarily imply the generation of eddies [Nof and Pichevin, 1996]. These eddies flow northwestward (with observed translation speeds of 7$14 \mathrm{~km} /$ day and surface swirl velocities of $50-100 \mathrm{~cm} / \mathrm{s}$ ) toward the Caribbean sea on a course parallel to the South American coastline [Richardson et al., 1994; Fratantoni et al., 1995]. Rings translation lasts 3-4 months until their destruction through interactions with abrupt topography in the vicinity of the Lesser Antilles [Fratantoni and Glickson, 2002]. Several studies [Pauluhn and Chao, 1999; Goni and Johns, 2001; Barnier et al., 2001; Fratantoni and Glickson, 2002] suggest that the generation of anticyclonic rings (with mean diameters up to $400 \mathrm{~km}$ and penetrating depths approaching $1000 \mathrm{~m}$ ) is permanent the year long and produces five to eight eddies per year according to source [Didden and Schott, 1993; Richardson et al., 1994; Ffield, 2005], yet no particular seasonality was found in their generation [Fratantoni and Glickson, 2002].

[5] Therefore two circulation patterns are still in debate. The first speculates that the NBC retroflection would stop from March to June. Such a thesis is substantiated by several studies [e.g., Schott et al., 1998; Hellweger and Gordon, 2002; Fonseca et al., 2004]. The latter study is based on eight years of TOPEX/Poseidon altimeter-derived sea height anomaly during which the NBC retroflection location could not be identified from April to June. To reconcile this theory with the observed permanent ring generation, Barnier et al. [2001] suggest that when NBC retroflection vanishes, ring generation could be attributed to the sole NBC retroflection into the EUC which is a permanent circulation feature.

[6] The second pattern relies on recent works [Fratantoni and Glickson, 2002; Lumpkin and Garzoli, 2005; Fratantoni and Richardson, 2006] which support the theory that the NBC retroflection could be continuous the whole year long and that the latitude of the NBC retroflection front is directly related to the intensity of the NBC [Garzoli et al., 2004].

[7] Hence some of the mechanisms inherent in this complex oceanic system still need to be confirmed. Furthermore, important additional questions remain unanswered such as, the nature of the cross-shelf interaction of the NBC current with the coastal currents observed over the continental shelf in front of the South American coast. These coastal currents will have a major role in the fate of the Amazon plume which spreads northwestward over the continental shelf as long as it is not rerouted eastward by the NBC retroflection and thus deserve particular attention. On the Amazon continental shelf, the AMASSEDS (A Multidisciplinary Amazon Shelf Sediment Study) surveys have provided important information on the topic: Moored current measurements from mid-February to mid-June 1990 showed that the surface current as well as those below the plume layer were northwestward, hence parallel to the NBC
[Geyer et al., 1996; Johns et al., 1998]. Geyer et al. [1996] suggest that the large alongshore mean currents observed on the whole water column of the inner shelf could be driven by a large-scale alongshore and nearly barotropic pressure gradient, the origin of which is unknown though likely to be associated with the dynamics of the NBC. According to Lentz [1995], no clear statistical correlation between the shelf and slope currents was found, but he noticed that the major flow events in the NBC are also detected in the inner shelf.

[8] The NOAA Subtropical Atlantic Climate Studies (STACS) program provided additional information on the cross-shelf interactions through three moorings deployed in waters offshore of the shelf break, in 500, 2000 and $3400 \mathrm{~m}$ water depths, respectively, near the mouth of the Amazon river. The corresponding data (from September 1989 to January 1991) combined with the AMASSEDS data describe a transition from a weak and more coastally trapped NBC during spring, with much of its transport confined over the shelf and upper continental slope, to a broader flow infall spanning over most of the width of the continental slope, thicker in depth and stronger in intensity [Johns et al., 1998].

[9] Currents and hydrology on the French Guiana continental shelf were investigated through oceanographic cruises in June 1976 and December 1990 (GUYANTE) [see Pujos and Froidefond, 1995], in 1989-1990 (NOE) [see Colin et al., 1994], May 1996 (SABORD-0 within the ETAMBOT program) [Equipe Etude du Transport Atlantique Méridien dans le Bassin Ouest Équatorial, 1997] and April 1999 (CHICO-0) (unpublished data). Additional surveys were undertaken outside the shelf off French Guiana during the World Ocean Circulation Experiment (WOCE) cruises (CITHER-1 and ETAMBOT in 1993, 1995 and 1996 [see Bourlès et al., 1999]. Moored current meter measurements have also been carried out on the outer shelf off French Guiana [Colin et al., 1994] and on the continental margin near the 'Demerara rise' [Johns et al., 1990], but no similar measurements have been undertaken so far on the French Guiana inner shelf to our knowledge. The five months mooring survey presented in this paper is therefore intended to partially make up for the lack of data and knowledge addressing currents seasonal variability on the French Guiana continental shelf, with a special emphasis on the interactions between outer shelf mesoscale structures and the hydrodynamics over the shelf.

\section{Moorings Description}

[10] Three moorings were deployed on the French Guiana continental shelf during the CHICO- 1 cruise (4-15 October 2003) and were retrieved in late February 2004 at the end of the PIRATA FR12 cruise (28 January to 20 February 2004). Two of these moorings, namely, M1 and M3, were located over the shelf while M2 was deployed at the outer edge of the shelf. Their exact positions and main characteristics are reported in Figures 1 and 2 and Table 1. These moorings were intended to give an insight into the hydrodynamics and hydrology over the shelf during a period of time overlapping both the dry and the rainy seasons in French Guiana. At this time, the Inter Tropical Convergence Zone (ITCZ) migrates southward from its northernmost position, 


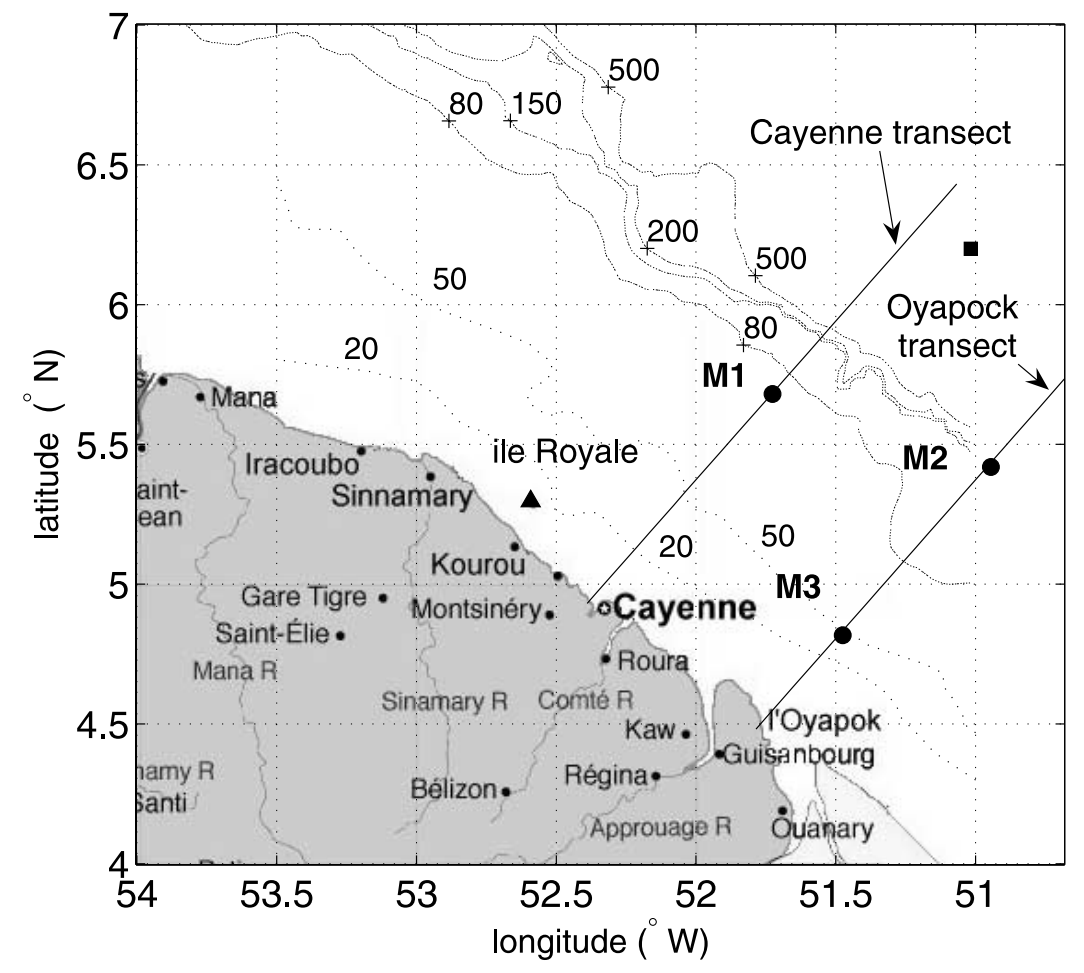

Figure 1. Mooring positions over the French Guiana continental shelf. Moorings M1, M2, and M3 are located at 105, 140, and $40 \mathrm{~km}$ from the coast, respectively. The black square refers to the Colin et al. [1994] mooring position.

with consequences on the precipitation regime, the atmospheric forcing on the regional hydrodynamics [Colin et al., 1994] and the location of the NBC retroflection [Fonseca et al., 2004].

[11] The other main purpose of these moorings is related to the numerical code Mobeehdycs [Chevalier et al., 2004] that enables the simulation of the marine circulation over the shelf, in order to proceed to validating operations as well as getting more information to refine the numerical boundary conditions [Bourret et al., 2005]. Hence two moorings (i.e., M2 and M3) have been deployed on the eastern shelf boundary, which was considered as an entrance boundary for the water flux according to what was believed prior to the present survey. M2 was also situated on the oceanic boundary, near the shelf break. Finally, the last mooring M1 was over the shelf and formed a triangle with M2 and M3. The purpose of such a configuration is again dictated by some constraints inherent to the model validation by comparing simulated and calculated current profiles at M1 while those at the M2 and M3 sites are known. This should be done in future work.

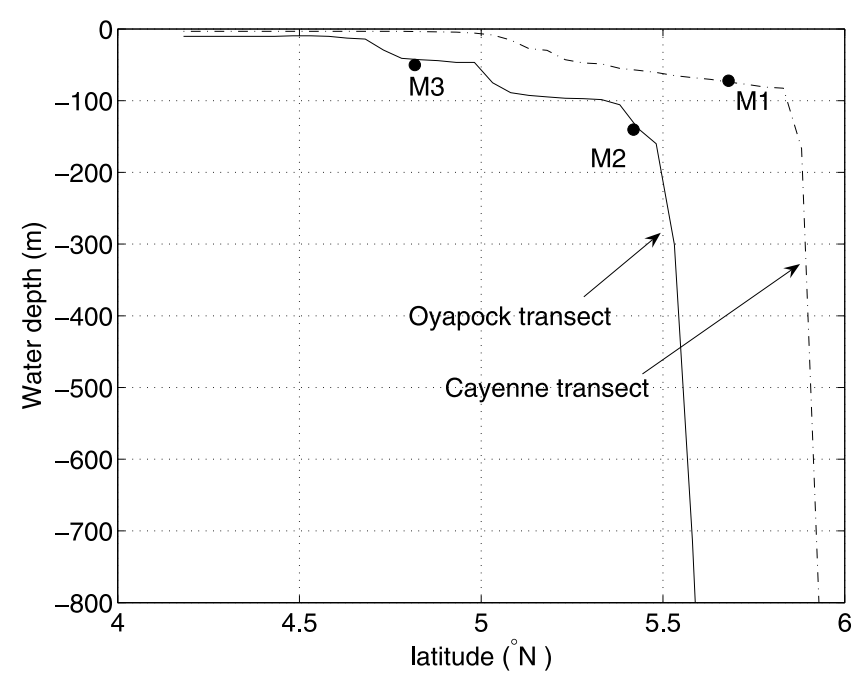

Figure 2. Mooring positions over the French Guiana continental shelf. 
Table 1. Main Characteristics of the Moorings ${ }^{\mathrm{a}}$

\begin{tabular}{|c|c|c|c|c|c|c|}
\hline \multirow[b]{2}{*}{ Mooring } & \multirow[b]{2}{*}{ Latitude and Longitude } & \multirow[b]{2}{*}{ Water Depth, m } & \multicolumn{3}{|c|}{ Instrument } & \multirow{2}{*}{$\begin{array}{l}\text { Inertial Oscillations } \\
\text { Period, hours }\end{array}$} \\
\hline & & & Nature & Reference & Depth, m & \\
\hline M1 & $\begin{array}{c}5^{\circ} 40.83^{\prime} \mathrm{N} \\
51^{\circ} 43.57^{\prime} \mathrm{W}\end{array}$ & 72.3 & $\begin{array}{c}\mathrm{CM}(\mathrm{T}, \mathrm{S}, \mathrm{P}) \\
\mathrm{CM}(\mathrm{lost}) \\
\mathrm{CM}(\mathrm{T}, \mathrm{S}, \mathrm{P})\end{array}$ & $\begin{array}{c}11862 \\
10980 \\
9548\end{array}$ & $\begin{array}{l}26 \\
42 \\
58\end{array}$ & 120.7 \\
\hline M2 & $\begin{array}{c}5^{\circ} 25.16^{\prime} \mathrm{N} \\
50^{\circ} 56.71^{\prime} \mathrm{W}\end{array}$ & 150.3 & $\operatorname{ADCP}(\mathrm{T}, \mathrm{P})$ & & 130 & 126.5 \\
\hline M3 & $\begin{array}{c}4^{\circ} 49.05^{\prime} \mathrm{N} \\
51^{\circ} 28.52^{\prime} \mathrm{W}\end{array}$ & 50.3 & $\begin{array}{l}\mathrm{CM}(\mathrm{T}, \mathrm{S}, \mathrm{P}) \\
\mathrm{CM}(\mathrm{T}, \mathrm{S}, \mathrm{P})\end{array}$ & $\begin{array}{l}9097 \\
9098\end{array}$ & $\begin{array}{l}22 \\
36\end{array}$ & 142.3 \\
\hline
\end{tabular}

${ }^{a}$ The current meters (CM) were of type Aanderaa RCM7. T means equipped with a temperature sensor; $\mathrm{S}$ means equipped with a conductivity sensor; and $\mathrm{P}$ means equipped with a pressure sensor.

[12] Moorings instrumentation consisted of 5 Aanderaa current meters of type RCM7, an RDI $75 \mathrm{kHz}$ Acoustic Doppler Current Profiler (ADCP) and additional sensors that were shared out between M1, M2 and M3 as reported in Table 1. The middle current meter on M1 was unfortunately lost during the retrieving operation and the pressure sensor of current meter $11862\left(\mathrm{M}_{\text {top }}\right)$ failed. The ADCP was positioned near the sea bottom and directed toward the water surface. Its range of acoustic penetration was subdivided into 43 uniformly sized cells $3 \mathrm{~m}$ in height. Accounting for the high reverberation of the sea surface, data from the last $10 \%$ of the range to the surface are lost. The effective available ADCP velocity measurements are therefore in the depth range $[13 ; 118] \mathrm{m}$.

\section{Currents Analysis}

[13] Prior knowledge of the French Guiana continental shelf hydrodynamics is mainly due to the GUYANTE, NOE, SABORD-0 and CHICO-0 surveys and reveals that the coastal current is northwestward with intensities in the range of $[0.3-1.1] \mathrm{m} \mathrm{s}^{-1}$. In addition, the primary tidal forcing on the shelf is semidiurnal ( $M_{2}$ component) with amplitudes varying along the coast from 80 to $90 \mathrm{~cm}$ (data from the French Service Hydrographique et Océanograhique de la Marine (SHOM)). In the present survey, the tidal constituents have been calculated from the velocity records through the harmonic analysis method [Foreman, 1978]. 36 constituents have been extracted for each mooring. The semimajor axis is in the order of $12.4 \mathrm{~cm} / \mathrm{s}$ for the $M_{2}$ wave and velocity records provide mean $S_{2} / M_{2}$ and $N_{2} / M_{2}$ ratios of 0.30 and 0.25 , respectively. This indicates a large springneap variation $\left(\left(M_{2}+S_{2}\right) /\left(M_{2}-S_{2}\right)=1.87\right)$ and monthly variation $\left(\left(M_{2}+S_{2}+N_{2}\right) /\left(M_{2}-N_{2}-S_{2}\right)=3.48\right)$ in the semidiurnal forcing. The two main diurnal constituents, $K_{1}$ and $O_{1}$, have a much lower semimajor axis amplitude.

\subsection{Current Direction}

[14] Time series of current vectors are presented in Figures 3 and 4 . Note that the two current meters of the shallowest mooring (M3) were subjected to marine fouling: the lowest current meter on M3 (9098) stopped working at the end of December 2003, while the rotor of the second one (9097) was restricted after 2880 hours of recording (i.e., in early February 2004).

[15] At first glance, the patterns of the different velocity records are quite similar (see Figures 3 and 4) and exhibit two distinct periods: the first period of the survey shows a horizontal velocity current of variable direction while in the rest of the mooring period, the current is roughly unidirectional toward the northwest. The transition between both regimes occurs between late November $\left(\mathrm{t}_{\text {trans }}=1260 \mathrm{~h}\right)$ and mid-December $\left(\mathrm{t}_{\text {trans }}=1725 \mathrm{~h}\right)$ according to the site and the depth. It is noticeable that this transition takes place roughly at the same moment as the change between the dry and rainy season. For better analysis, the survey period has therefore been split into two periods and the aforementioned transition time delimits the end of the first period. These

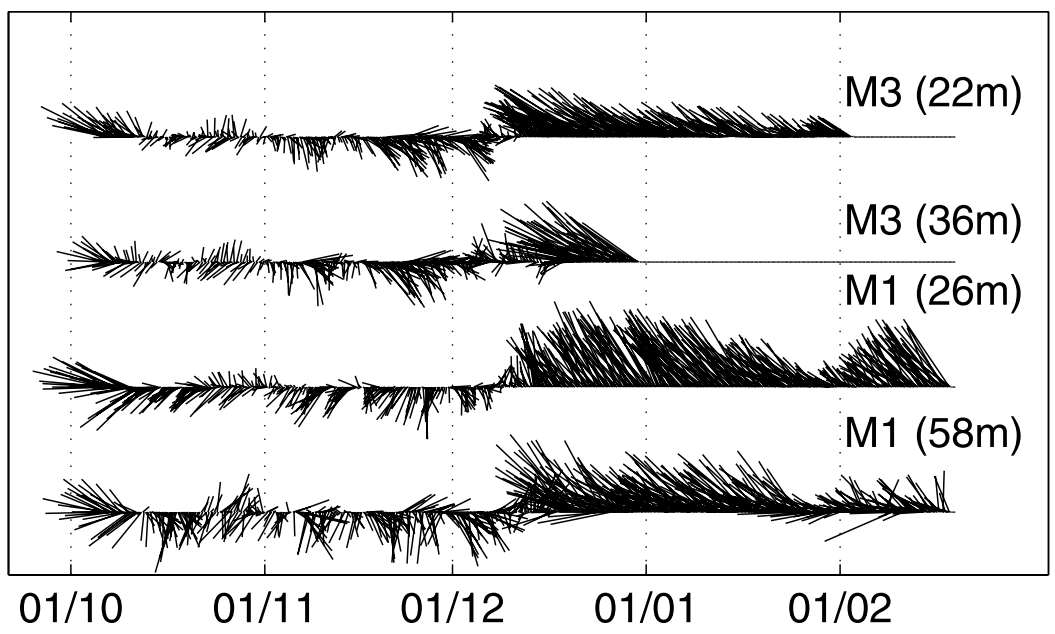

Figure 3. Stick diagrams (6-hour subsampling) at the M1 and M3 moorings. 


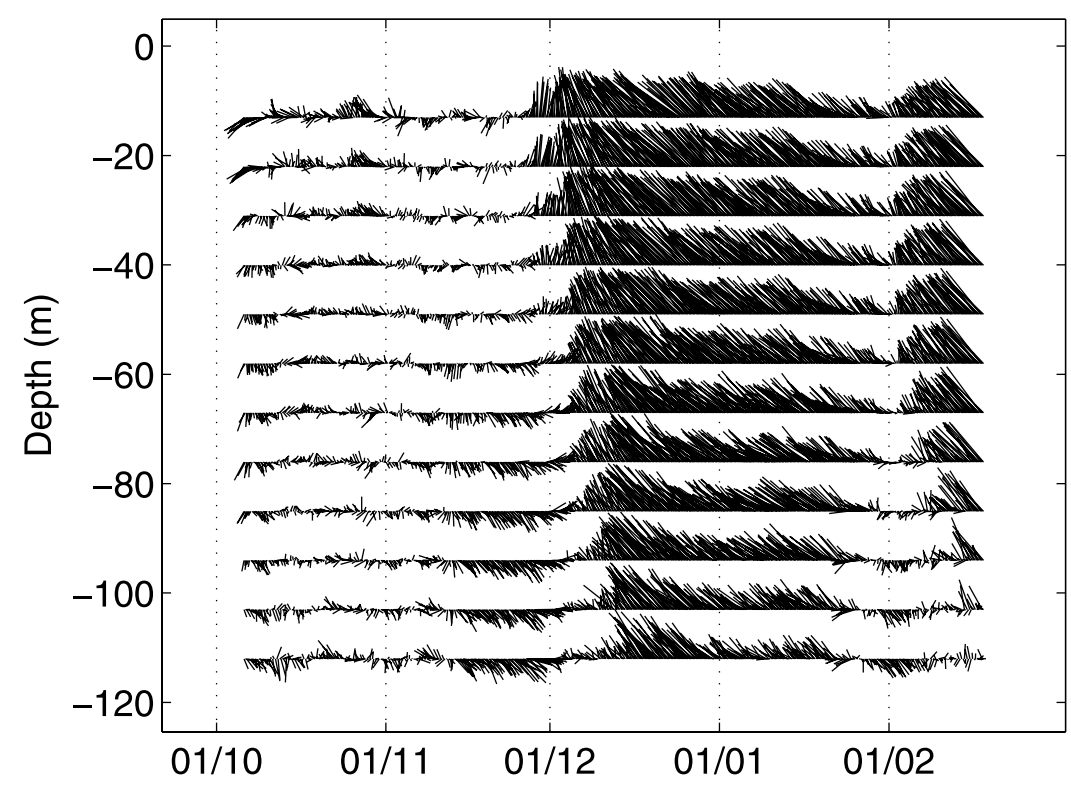

Figure 4. ADCP stick diagrams (6-hour subsampling) at several depths at the M2 mooring.

periods will be referred to as the first and the second period of the survey in the rest of this paper. During the first period (from October to December), the direction of the horizontal current oscillates at the M2 mooring, while at the M3 mooring, SE and NW currents prevail. During the same period, the M1 mooring exhibits a particular circulation pattern in that the velocity direction is mainly S-SW.

[16] During the second period, the records at the three moorings indicate a northwestward flow. Note that this northwestward flow concerns the whole water column in M2. It first establishes over the shelf edge (at M2) and then is felt a few days later over the continental shelf (see Figures 3 and 4). This lag time will be discussed in further detail later (see section 5).

\subsection{Current Speed}

[17] Current speed at the three moorings are presented in Figure 5 in which time $t=0$ corresponds to 6 October 2003 at 0100:00 GMT. The same two periods as those observed on stick plots are evidenced on velocity diagrams, with transition occurring near the beginning of December.

[18] During the first period (between October and early December), the current modules are in the range $[0 ; 0.8] \mathrm{m} / \mathrm{s}$ and the corresponding mean values (see Table 2 ) are slightly higher seaward (at M1 and M2). During the second period, current velocity reaches values as high as $1.5 \mathrm{~m} / \mathrm{s}$ at the nearest slope mooring (M2) in mid-December. Similar intensities were already observed by Colin et al. [1994] in September 1989 and 1990 on the Cayenne transect but at higher latitudes $\left(6^{\circ} \mathrm{N}-8^{\circ} \mathrm{N}\right)$ over the shelf break $(300 \mathrm{~m}$ water depth). For comparison, two AMASSEDS moorings (mid-February to mid-June 1990) located near the Amazon mouth at 17 and $65 \mathrm{~m}$ water depths, respectively, yielded remnant northwestward surface currents estimated at $0.46 \mathrm{~m} / \mathrm{s}$ at the inner shelf site and $0.83 \mathrm{~m} / \mathrm{s}$ midshelf once the wind stress contribution was removed [Geyer et al., 1996; Johns et al., 1998]. Moreover, at both our inner shelf moorings (M1 and M3), the mean current velocity in the second period (in boreal winter) is roughly twice that observed during the first period (boreal fall) while at the near slope mooring M2, current velocity increases by factor 4 during the second period (see Table 2 and Figure 6).

[19] During the second period, it is noticeable that current velocities start to decrease simultaneously at the three moorings around mid-December, pass through a minimum in the beginning of February and increase again a few days later. Since the survey was stopped around mid-February, the interpretation of such a phenomenon is delicate but a likely explanation for this episode is provided in section (5) in the light of Moderate Resolution Imaging Spectroradiometer (MODIS) chlorophyll images.

[20] Figure 7 exhibits the daily averaged vertical profiles of alongshore horizontal velocities at the M2 mooring. In fall, the current is nearly barotropic between 13 and $118 \mathrm{~m}$ in depth with the exception of the beginning of the survey. Indeed, during the 6-19 October period, the vertical profiles (bold profiles in Figure 7) denote a highly baroclinic flow with southwestward near-surface currents and southeastward deeper ones. This is likely due to the presence of a low-salinity surface layer which is strongly influenced by local wind. As a matter of fact, salinity vertical profiles measured at the same place as the M2 mooring location during the CHICO-1 cruise (9 October) revealed the presence of a low-salinity surface layer extending down to $30 \mathrm{~m}$ (results not shown).

[21] During the boreal winter (from December to February), all the daily averaged velocity profiles exhibit a strong vertical shear between 80 and $118 \mathrm{~m}$ in depth while the upper water column is quite homogeneous in current speed and direction. Such a vertical distribution is characteristic of the bottom shear stress that slows down water displacement near the bottom.

[22] Finally, the proper presentation of the velocity measurements which has been done in the two previous sections will be enriched in section (5) with the discussion of these data in light of satellite images (Figure 8).

[23] MODIS-Aqua satellite images covering the mooring period have been downloaded from the OceanColor Web 




Figure 5. Current intensity at the three moorings. Note that the vertical scale for M2 (ADCP) is twice those for M1 and M3.

site (http://oceancolor.gsfc.nasa.gov/cgi/level3.pl) in order to investigate the geographic distribution of Amazon waters during this period. It has indeed been evidenced by Hu et al. [2004] that, in this area, the colored water mass provided by "chlorophyll" images could be associated with riverine discharge from the Amazon River. The "chlorophyll" level 3 images produced weekly were chosen for this study. They are composite images of cloud-free acquisitions for each ocean pixel and data are binned into $4.6 \mathrm{~km}$ by $4.6 \mathrm{~km}$ resolution cells. The MODIS bio-optical "chlorophyll" algorithm establishes an empirical relation between ocean color and the photosynthetically active phytoplankton pig- ment but leads to an important overestimation of phytoplankton concentrations in presence of mineral particles [Froidefond et al., 2002]. These "chlorophyll" data images are therefore only usable as a tracer of the Amazon waters.

\section{Salinity and Temperature Data}

[24] The upper layer (approximately the upper $300 \mathrm{~m}$ of the water column) of the western tropical Atlantic have been depicted in many earlier studies [e.g., Wilson et al., 1994; Schott et al., 1998; Bourlès et al., 1999]. It includes two near-surface layers, the first extending from the sea surface 
Table 2. Mean Current Horizontal Velocities ${ }^{\mathrm{a}}$

\begin{tabular}{|c|c|c|c|c|c|c|c|}
\hline \multirow[b]{2}{*}{$\underline{\text { Site }}$} & \multirow[b]{2}{*}{ Instrument Depth, m } & \multirow[b]{2}{*}{ Record Length, hours } & \multicolumn{2}{|c|}{ Record } & \multicolumn{3}{|c|}{ Seasonal Averages } \\
\hline & & & Mean & SD & {$\left[0 ; \mathrm{t}_{\text {trans }}\right]$ Mean } & {$\left[\mathrm{t}_{\text {trans }} ; \mathrm{t}_{\text {end }}\right]$ Mean } & {$\left[\mathrm{t}_{\text {trans }} ; 2500 \mathrm{~h}\right]$ Mean } \\
\hline M1 & 26 & 3256 & 0.44 & $(0.26)$ & 0.26 & 0.57 & 0.6 \\
\hline M1 & 58 & 3256 & 0.28 & $(0.16)$ & 0.19 & 0.35 & 0.4 \\
\hline M2 & 25 & 3252 & 0.75 & $(0.51)$ & 0.21 & 1.10 & 1.24 \\
\hline M2 & 35 & 3252 & 0.72 & $(0.51)$ & 0.18 & 1.06 & 1.18 \\
\hline M2 & 55 & 3252 & 0.66 & $(0.48)$ & 0.20 & 1.00 & 1.14 \\
\hline M3 & 22 & 2881 & 0.27 & $(0.18)$ & 0.17 & 0.35 & 0.39 \\
\hline M3 & 36 & 2065 & 0.2 & $(0.17)$ & 0.15 & 0.27 & $0.27^{\mathrm{b}}$ \\
\hline
\end{tabular}

${ }^{a}$ Velocities are given in $\mathrm{m} \mathrm{s}^{-1}$. SD is standard deviation; $\mathrm{t}_{\text {trans }}$ is the transition time between the two periods (see text); $\mathrm{t}_{\text {trans }}=1524,1710,1468.5,1725$, $1258.5,1260$, and 1382 hours for $\mathrm{M}_{\text {top }}, \mathrm{M} 1_{\text {bot }}, \mathrm{M} 2(25 \mathrm{~m}), \mathrm{M} 2(35 \mathrm{~m}), \mathrm{M} 2(55 \mathrm{~m}), \mathrm{M} 3_{\text {top }}$, and $\mathrm{M} 3_{\text {bot }}$ recorders, respectively. The third column shows $t_{\text {end }}$.

${ }^{\mathrm{b}}$ For the M3 $(36 \mathrm{~m})$ current meter, the mean velocities between $\mathrm{t}_{\text {trans }}$ and $\mathrm{t}_{\text {end }}$, and $\mathrm{t}_{\text {trans }}$ and 2500 hours are equal since $\mathrm{t}_{\text {end }}=2065$ hours.

to the 24.5 isopycnal while the second is bounded by the 24.5 and 26.75 isopycnals [Wilson et al., 1994]. The former contains the core of the NBC and the NECC and originates from North and South Atlantic Subtropical waters (NAW and SAW) characterized by high salinities up to 36.8 [Bourlès et al., 1999] and high temperatures exceeding $26^{\circ} \mathrm{C}$ [Schott et al., 1998]. These oceanic waters are mixed with fresh surface waters from the Amazon river above the equator. This induces the formation of a steep halocline in the 3-30 m depth range and the associated pycnocline acts as a barrier layer preventing vertical mixing. The fresh surface waters are generally associated with positive anomalies of the sea surface temperature (SST). Temperature rose above $28^{\circ} \mathrm{C}$ within the barrier layer and up to $29.5^{\circ} \mathrm{C}$ in May 1996 [Pailler et al., 1999]. Satellite SST measurements slightly modify this view: Ffield [2005] evidenced that the NBC carries relatively warm (cold) surface water into a relatively cold (warm) region in the first (second) half of the year. Lentz and Limeburner [1995] describe highly spatial variability in plume salinity (from 10 to 35 ) in the vicinity of the Amazon mouth, especially near the sea surface and average plume salinity is shown to increase monotonically toward the north.

[25] Salinity and temperature measured at the M3 and M1 moorings during this survey are presented in Figures 9 and 10 , respectively. After 23 January salinity records are not presented at the M3 and the M1(26 m) moorings since they contain too much noise to produce interpretable results. At the location of the M3 mooring, salinity values from 7 October to 29 November attest the presence of marine water at 22 and $36 \mathrm{~m}$ depths. This is consistent with measurements of the CHICO- 1 cruise (4-15 October 2003) which indicate that the Amazon river plume spreads over the southeasternmost part of the French Guiana continental shelf and therefore partly over our moorings, though with a halocline located very near the sea surface (between 5 and $10 \mathrm{~m}$ depth at the M1 and M3 moorings). Salinity decreases slowly around 29 November, and sharply from 23 December. It stabilizes at 25 one month later at a $36 \mathrm{~m}$ depth. This strong decrease in salinity is undoubtedly due to the arrival of Amazon plume waters over the shelf (see Figure 8d) and may be related to the setting up of the stable northwestward current which characterizes the second period of the survey (see section 5). Moreover, the aforementioned noise on the salinity records at the M1 and M3 moorings after 23 January is likely due to the fouling of the conductivity sensors inferred by the warm and rich Amazonian waters.
[26] Water temperature at M3 slowly decreases from 27.3 to $25^{\circ} \mathrm{C}$ between 6 October and mid-November. Afterward, temperature stabilizes around $25.2^{\circ} \mathrm{C}$ at a $36 \mathrm{~m}$ depth while it increases again at a $22 \mathrm{~m}$ depth. A sharp decrease in temperature is then observed at both depths around 6 December, a few days before the northwestward current builds up over the shelf. After this short episode, temperature increases again sharply at the same time as salinity decreases, and reaches values around $27.5^{\circ} \mathrm{C}$ once the Amazon river waters have spread over the continental shelf (see section 5 for more details). Temperature ultimately decreases again from early February up to around $25^{\circ} \mathrm{C}$ at both depths. This could be due to the fact that the plume is confined closer to the coast than it was previously, as suggested by Figures $8 \mathrm{~d}$ and $8 \mathrm{e}$.

[27] Salinity time series at the M1 mooring showed far less variability and the records at both depths ( 26 and $58 \mathrm{~m}$ ) exhibit quite similar tendencies: salinity is in the range 34.5-36 from the beginning of the survey up to 26 December. Afterward, salinity decreases during one month down to 33 and increases again slightly around

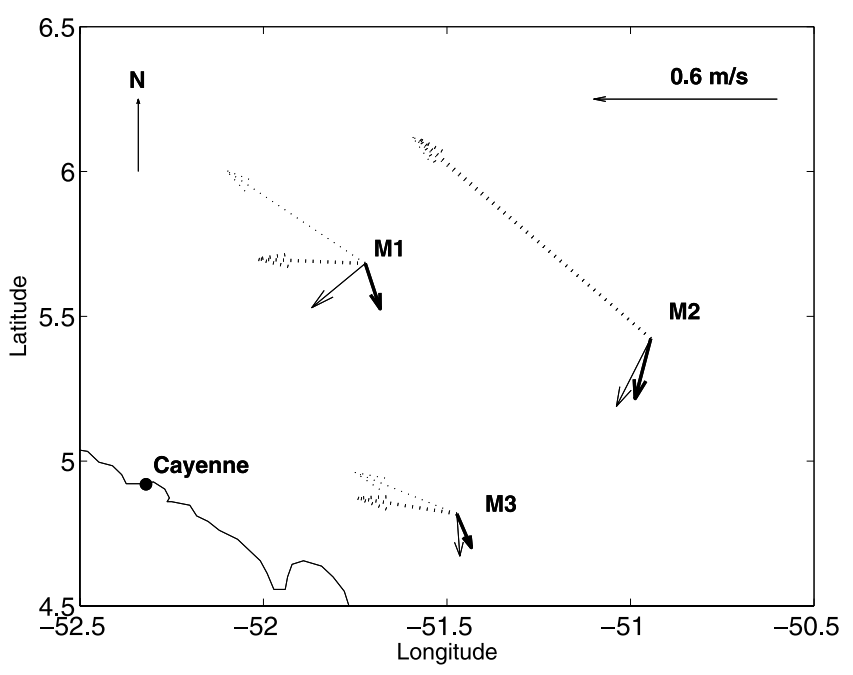

Figure 6. Mean horizontal velocities at M1 (26 m), M2 (25 m), and M3 (22 m) (thin line) and at M1 (58 m), M2 $(55 \mathrm{~m})$, and M3 (36 m) (thick line). These velocities are averaged over the first period from October to early December (solid line) and during the second period from early December to late February (dotted line). 

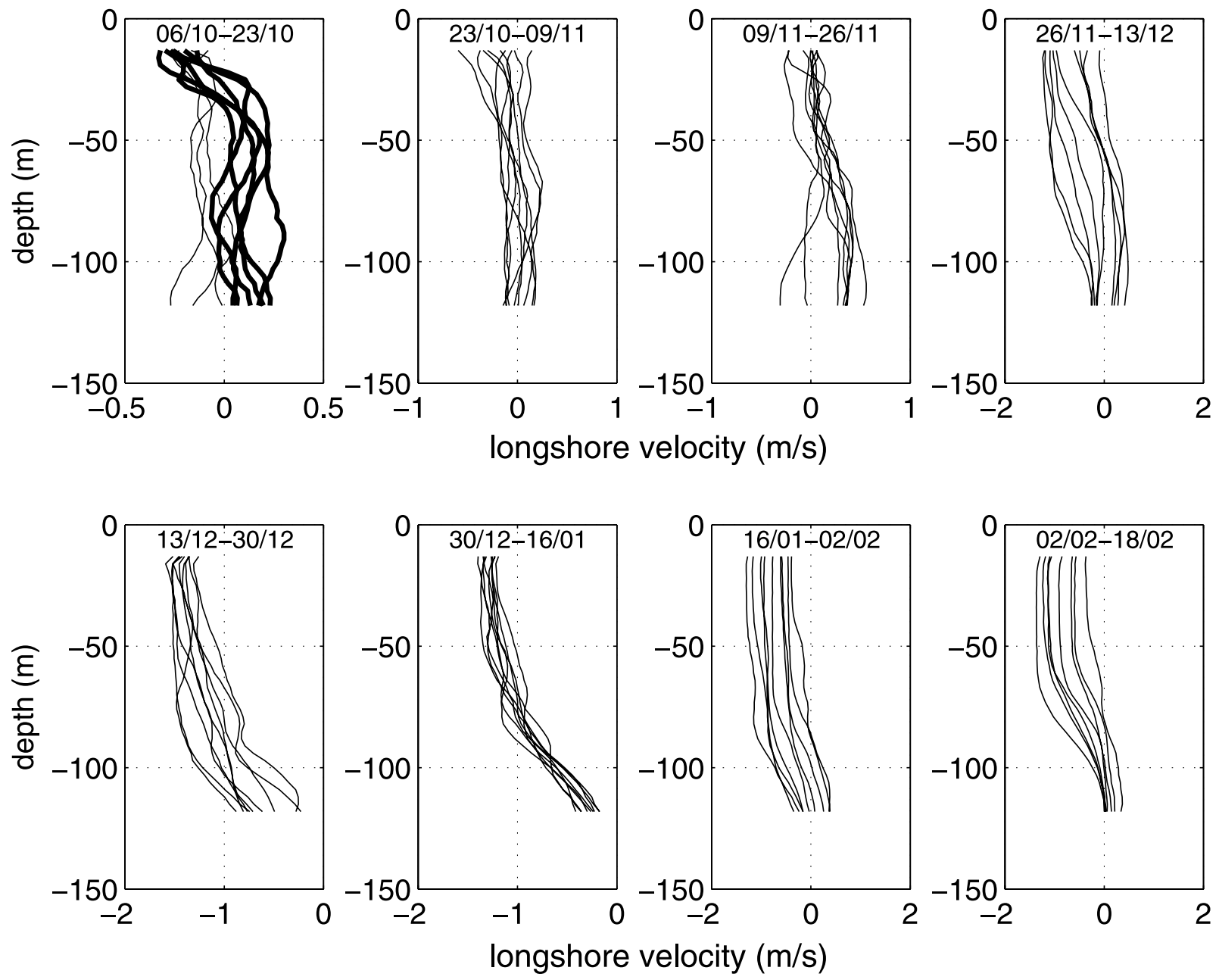

Figure 7. Daily vertical profiles of alongshore horizontal velocity at the M2 mooring (positive velocities are southeastward).

34 after 22 January at $58 \mathrm{~m}$. The pattern of the temperature time series at the M1 mooring is roughly the same at 26 and $58 \mathrm{~m}$ though with quantitative differences: from early October to early December, temperature decreases from 29.5 down to $24.5^{\circ} \mathrm{C}$ at $26 \mathrm{~m}$ and from 27 down to $21.5^{\circ} \mathrm{C}$ at $58 \mathrm{~m}$. As for the $\mathrm{M} 3$ records, temperature passes through a minimum in early December before the setting up of the northwestward current over the shelf. After mid-December, the temperature increases sharply up to $27-28^{\circ} \mathrm{C}$ at both depths but particularly at $58 \mathrm{~m}$. Finally, temperature decreases again after 22 January and this is accompanied by a slight increase in salinity at $58 \mathrm{~m}$. This again suggests that the plume has become more coastally trapped.

\section{Discussion}

[28] During the AMASSEDS survey, a strong correlation was found between the alongshore current variations in the plume layer and the local alongshore winds [Lentz, 1995]. In the present study, climatic data provided by Meteo France at three different sites, namely Ile Royale, Cayenne and Kourou have been used to investigate potential wind effect on the coastal currents over the French Guiana continental shelf (results not shown). No correlation between wind and current has been found either in boreal fall, or in winter when the Amazon plume has spread over the continental shelf. It is clear however, that our velocity measurements do not concern the sea surface layer which is more influenced by wind than subsurface waters. Moreover, high vertical stratification due to the presence of Amazon plume waters expanding over the shelf may reduce the transfer of wind kinetic energy to the subsurface layers in which our measurements were performed.

[29] By contrast, during the whole period of the survey, a strong correlation can be established between the mesoscale circulation features occurring outer shelf off French Guiana and the French Guiana continental shelf dynamics. We shall analyze these ocean-coast interactions on the basis of the mooring data presented in previous sections and MODIS ocean color images (Figure 8). For convenience in the discussion presented hereafter, the low-pass-filtered (cutoff frequency of $9.610^{-6} \mathrm{~Hz}(29 \mathrm{~h}$ period)) velocities recorded from 6 October to 30 December are provided in Figures 11, 12 , and 13, respectively, for the M1, M3, and M2 moorings.

[30] At first glance, it appears that during the first period of the survey (Figures 8a-8c), the three moorings are located between the NBC retroflection front and a NBC ring recently shed which has been roughly drawn in 


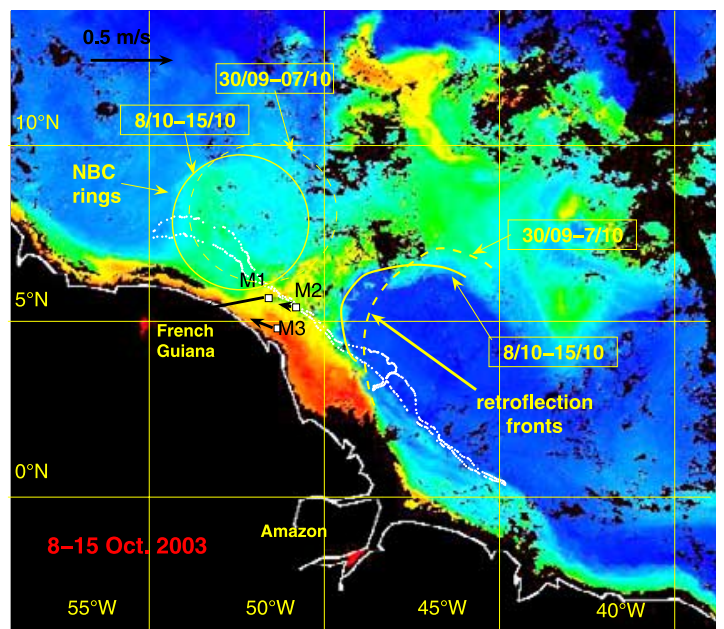

(a)

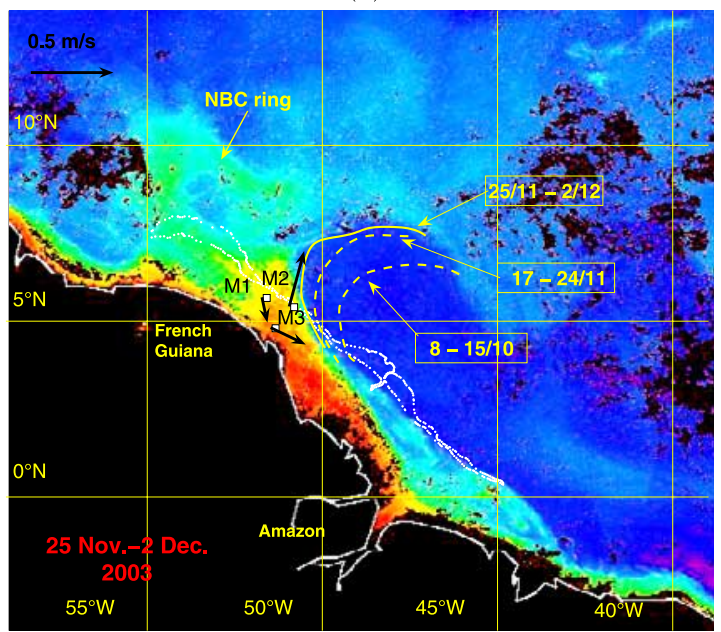

(c)

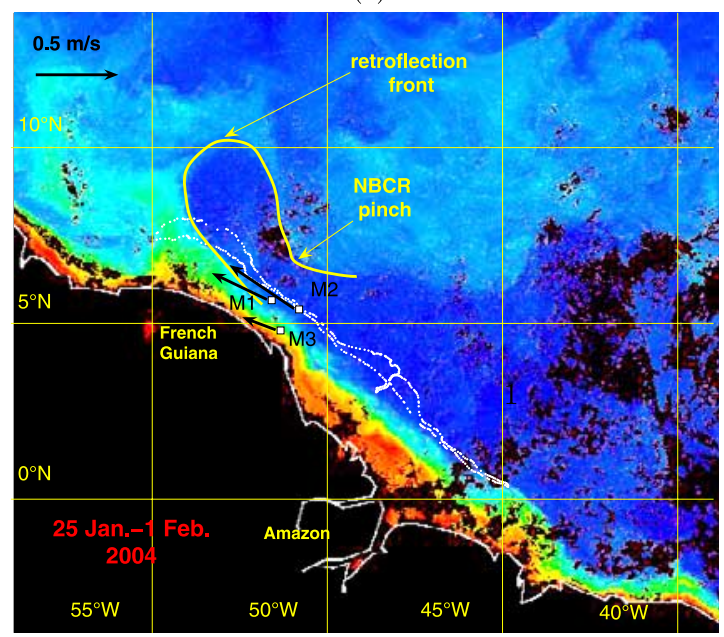

(e)

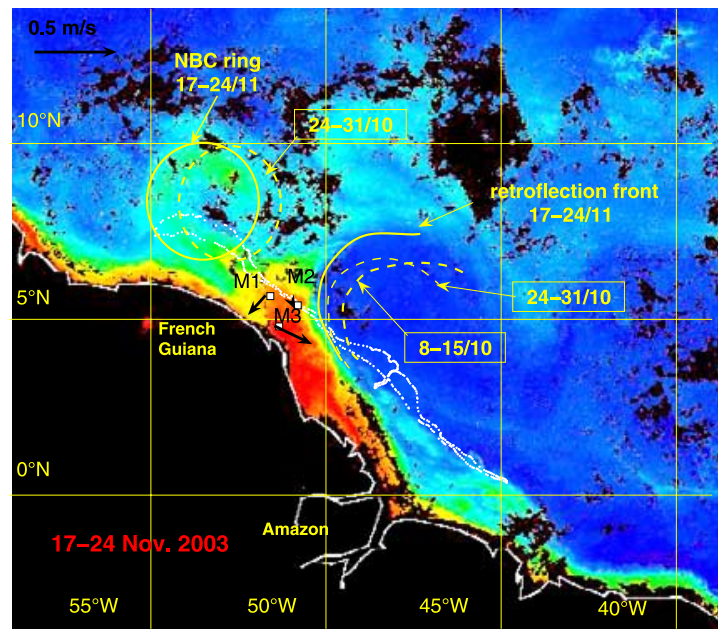

(b)

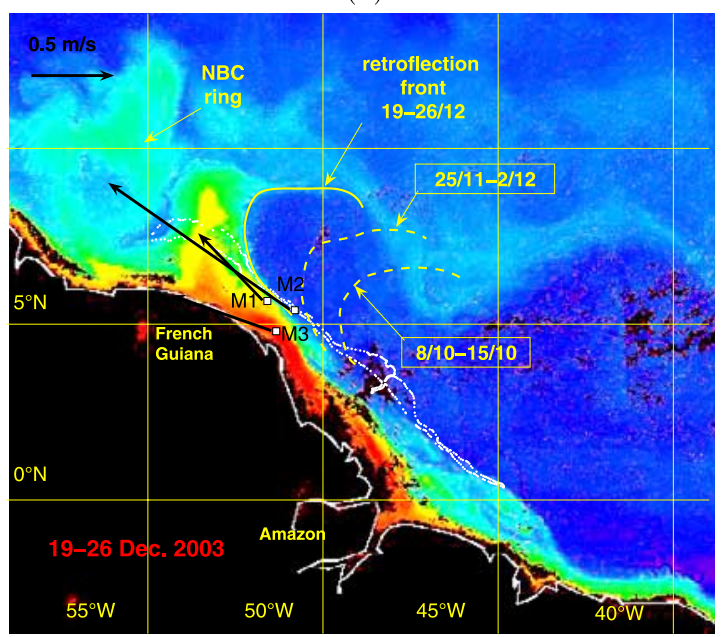

(d)

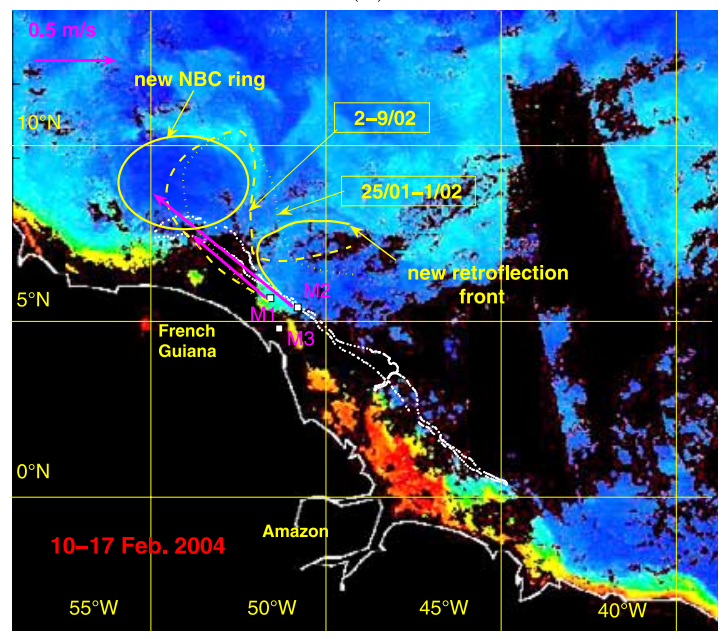

(f)

Figure 8. Composite MODIS images (weak averages) with superimposed currents at sites M1 (26 m), M2 $(25 \mathrm{~m})$, and M3 (22 m) and roughly drawn retroflection and NBC ring contours. The 200 and $1000 \mathrm{~m}$ isobaths are also represented (white dotted lines).

Figures $8 a-8 b$. It is worthwhile noticing that around $30 \%$ of the surface of this ring is over the continental shelf (shoreward of the $200 \mathrm{~m}$ isobath). Moreover, the influence of the anticyclonic NBC ring on the flow at the M1(26 m) current meter is evidenced in Figure 11 by the succession of continuous northwestward (during the 6-10 October period) and southwestward currents. The ring is initially (6-10 October) located northeast of the M1 mooring. This 

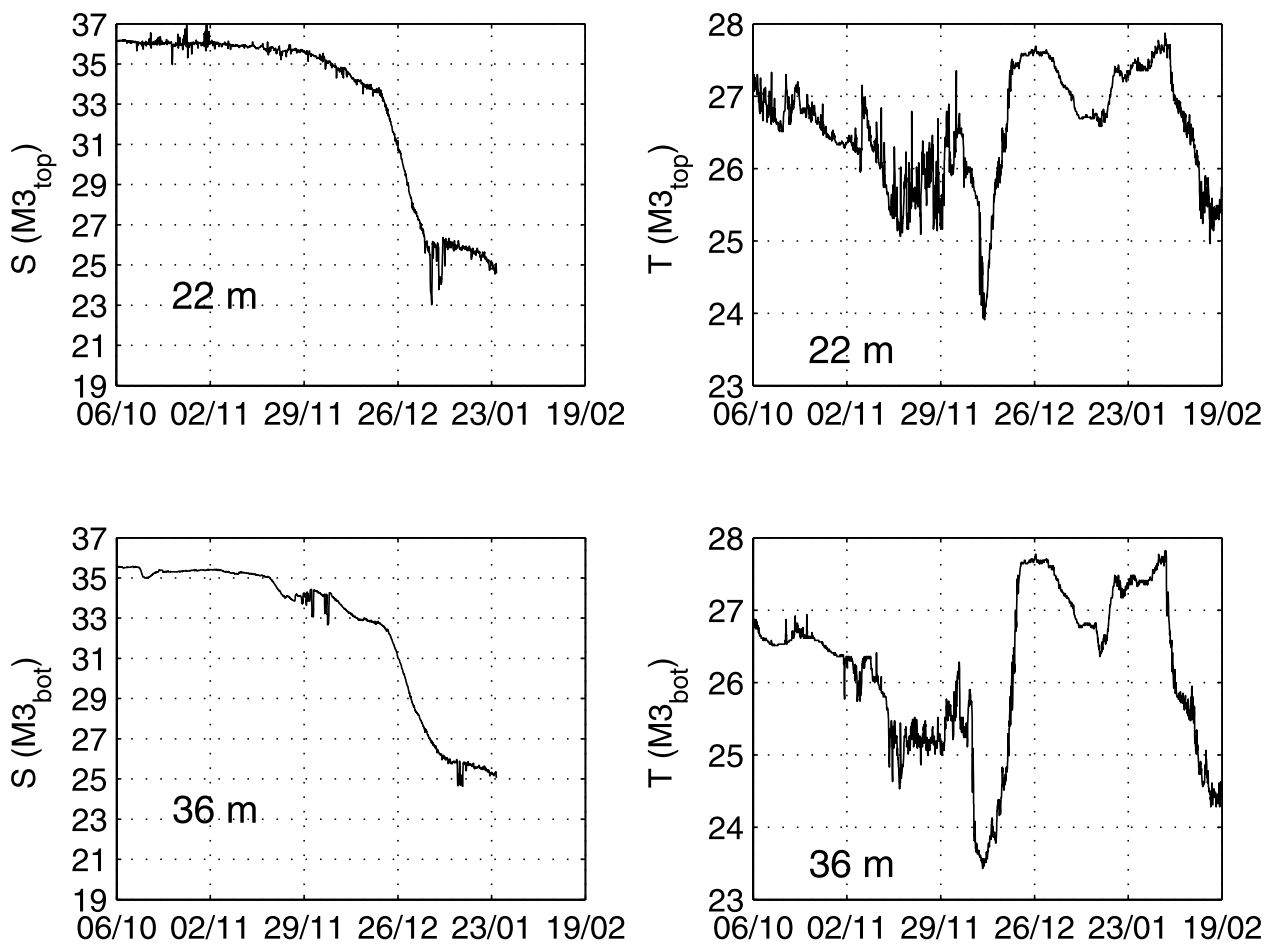

Figure 9. Salinity and temperature $\left({ }^{\circ} \mathrm{C}\right)$ variations at the $\mathrm{M} 3$ mooring.

infers northwestward currents at M1. Afterward, when the NBC ring has moved northwestward of M1, the current at M1 is southwestward and its intensity decreases progressively until 21 October as the NBC ring moves away (see ring contours in Figures $8 \mathrm{a}$ and $8 \mathrm{~b}$ ). After the latter date, the very weak currents of highly variable direction are interpreted as a period of transition in which adjustments are operating since the flow is submitted to the antagonist remote influences of both the NBC retroflection and the NBC ring.

[31] From early November to early December, the retroflection front continues its northwestward progression though it is still located southeast of the M1 mooring (see Figures $8 \mathrm{~b}$ and $8 \mathrm{c}$ ). It seems that during this period and because of the conservation of water mass, the northeast-
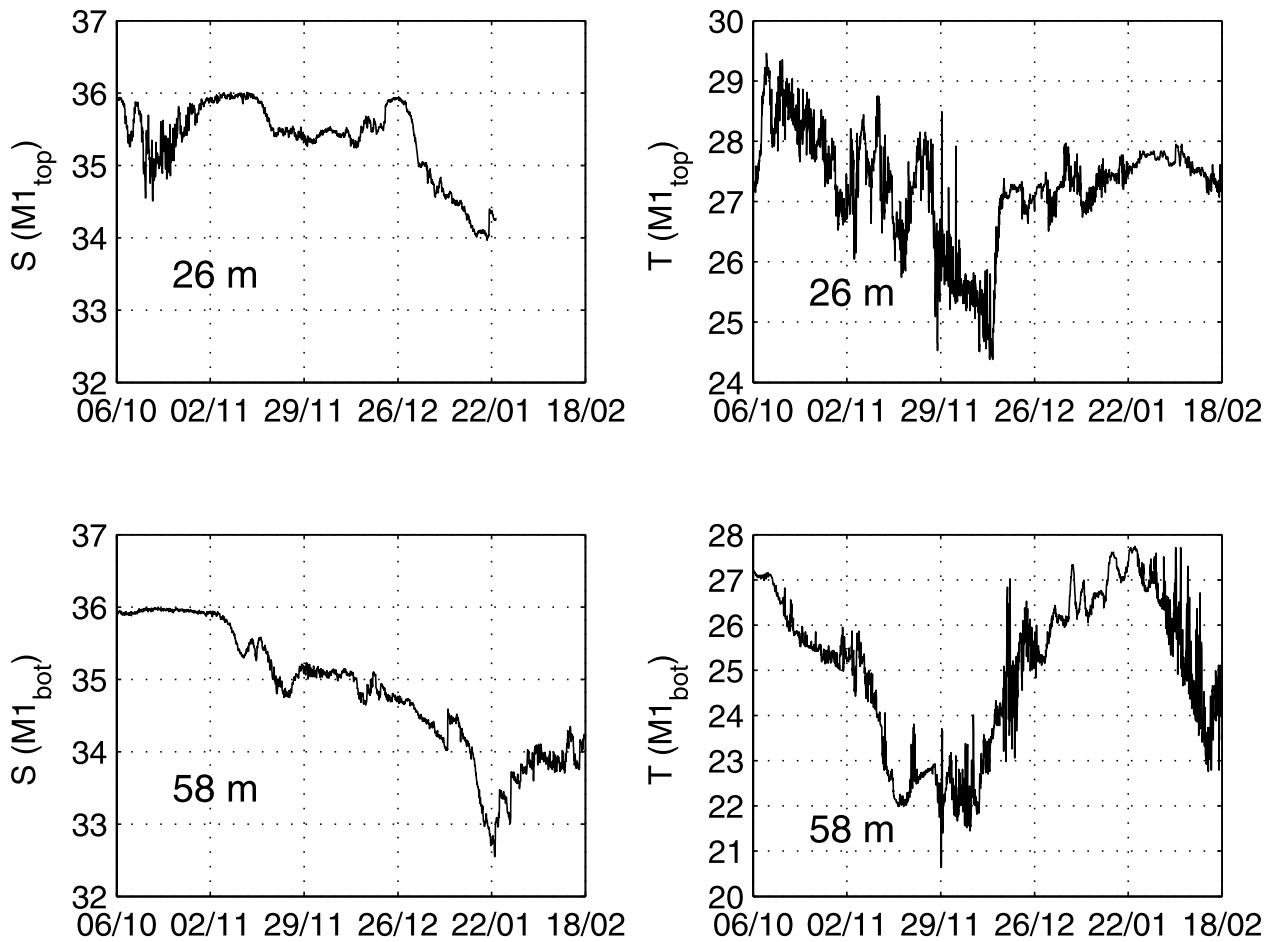

Figure 10. Salinity and temperature $\left({ }^{\circ} \mathrm{C}\right)$ variations at the M1 mooring. 

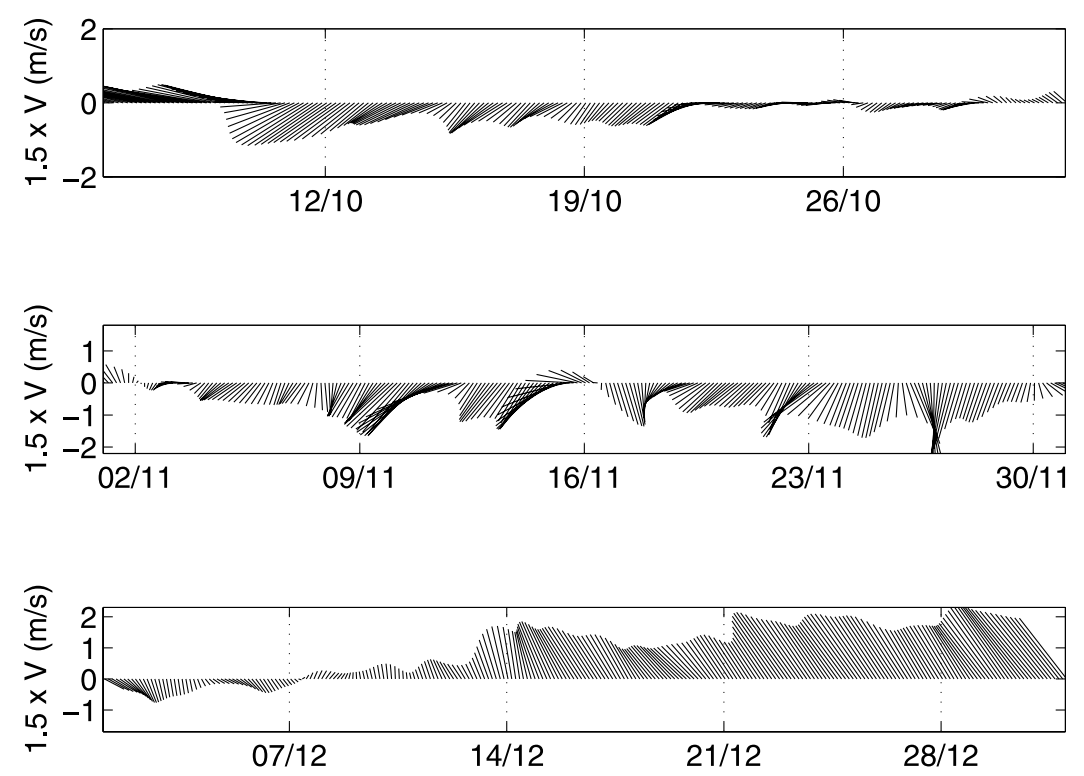

Figure 11. Zoom on mooring low-pass-filtered current time series during the first period (OctoberDecember) at the $\mathrm{M}_{\text {top }}(26 \mathrm{~m})$ current meter.

ward advection of water by the retroflection is compensated downstream of the front by a coastward advection of oceanic waters (see Figures 11 and $8 \mathrm{~b}$ ) that are colder and a little less salty (see Figure 10 during the $2-29$ November period). This southwestward compensation flow located downstream of the retroflection front has already been observed through ADCP measurements performed during the 28 August to 16 September 1989 cruise [Wilson et al., 1994]. The latter observations showed that the SW flow was also present in the upper layer between the sea surface and the 24.5 isopycnal (depth around $100 \mathrm{~m}$ ). Hence, though our measurements at the M1 mooring are restricted to the 26 and $58 \mathrm{~m}$ depth levels, it is likely that the whole water column in M1 is concerned by this compensation flow. This situation ends around 7 December and is followed about five days later by a drastically different pattern with strong and stable northwestward currents once the retroflection front has moved northwest of the M1 mooring (see Figures 11 and 8d).

[32] Current variations at the M3 mooring (22 m depth) are reported in Figure 12 and deserve an interpretation which is roughly similar to that provided for the M1 mooring with the exception of one point: during the month of November 2003, currents were southeastward at the M3 mooring while a S-SW compensation flow (see above) was recorded at the M1 mooring during the same period. We suggest that this compensation flow of relatively cold water (see the slight temperature decrease at the M3 mooring in
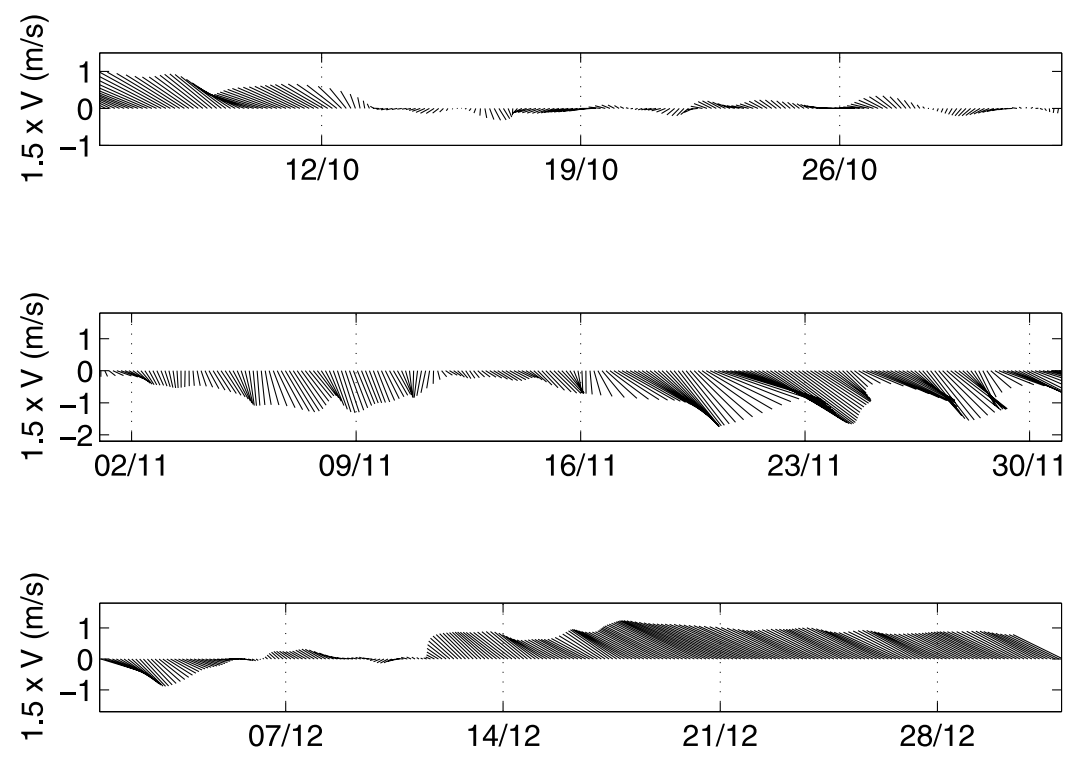

Figure 12. Zoom on mooring low-pass-filtered current time series during the first period (OctoberDecember) at the $\mathrm{M}_{\text {top }}(22 \mathrm{~m})$ current meter. 

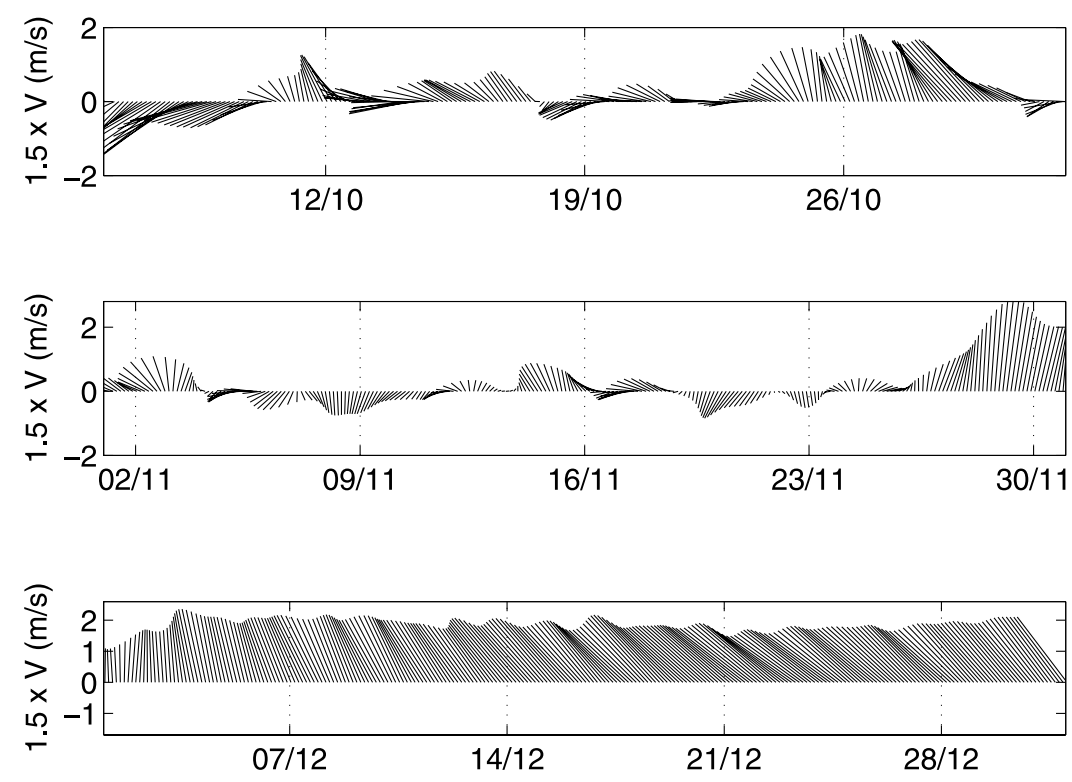

Figure 13. Zoom on mooring low-pass-filtered current time series during the first period (OctoberDecember) at the M2 mooring $(13 \mathrm{~m})$.

Figure 9 during the month of November) would have deviated southeastward as it came closer to the coast. The cross correlation (equation (1)) between the flow dynamics at the M3 and M1 moorings during the month of November has been calculated to reinforce this assumption. Considering two records $X_{i}(t)$ and $X_{j}(t)$, and their respective mean values $\bar{X}_{i}$ and $\bar{X}_{j}$ over the time period $T$, the cross-correlation $f(\tau)$ writes [Bendat and Piersol, 2000]:

$$
\begin{aligned}
f(\tau) & =E\left\{X_{i}^{*}(t) \cdot X_{j}^{*}(t+\tau)\right\} \\
& =\frac{1}{T} \int_{-T / 2}^{T / 2} X_{i}^{*}(t) \cdot X_{j}^{*}(t+\tau) \cdot d t
\end{aligned}
$$

where $E\{\}$ is the expected value operator, $X^{*}$ is the detrended value of $X(=X-\bar{X})$ and $\tau$ stands for the lag time between the two records. The maximum value of the crosscorrelation function during this period equals 0.49 and is obtained at a lag of 7.5 days. In addition, the time variations of the low-pass-filtered velocities at both the M1 and the M3 moorings are reported in Figure 14. For better comparison, these velocities have been normalized and detrended, and the M3 data series has been shifted forward 7.5 days. The good agreement between the low-frequency velocities at M1 and at M3 7.5 days later (though the weak value of the maximum correlation) evidences the correlation between the compensation flow at M1 and the SE flow observed at M3 during the month of November.

[33] In the beginning of October, the M2 mooring is near the southeastern edge of the NBC ring (see Figure 8a) and the permanent southwestward current during the 610 October period (see Figure 13) presumably denote the end of the ring influence on the flow at the M2 mooring (see the ring westward displacement between the weeks 30 September to 7 October and 8-15 October in Figure 8a). Beyond 10 October and up to 25 November, the retroflection front progresses northwestward (see Figures $8 \mathrm{~b}$ and $8 \mathrm{c}$ ) and therefore gets closer to the M2 mooring. During this period, highly oscillating current directions and small eddy structures (as in early November) are evidenced in Figure 13. The power spectral density of both velocity components over the 1-27 November period of record exhibits a peak around the $70 \mathrm{~h}$ period (results not shown) which indicates that these oscillations are regular but not due to inertial effects as the period of inertial oscillations is higher than $120 \mathrm{~h}$ (see Table 1).

[34] During the month of November, the M2 mooring is located near the interface between the aforementioned shoreward compensation flow and the seaward NBC retroflection front and water accumulation can be expected near such an interface. This water accumulation is evidenced by

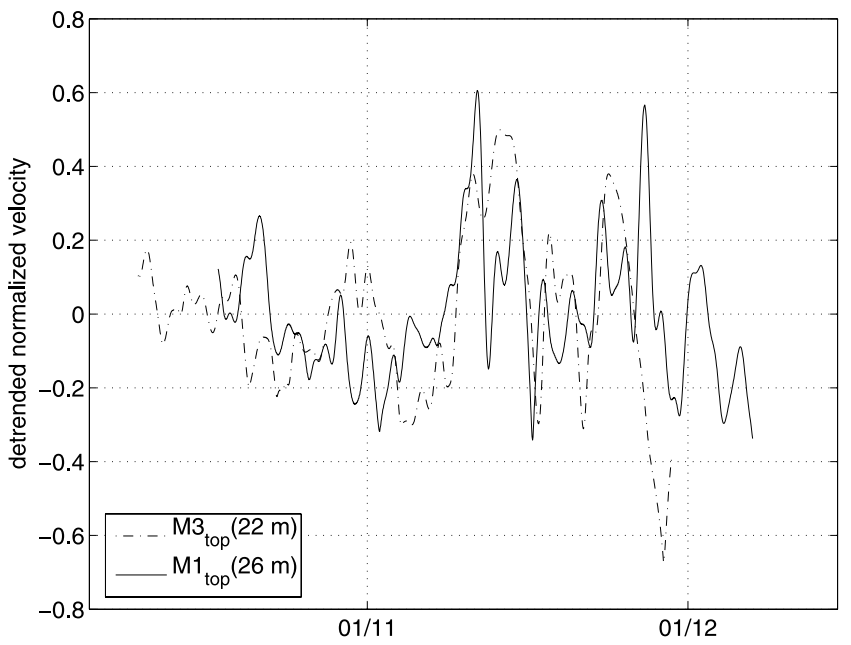

Figure 14. Correlation between the M1 and M3 velocities. Velocities have been low-pass filtered, normalized, and detrended. 

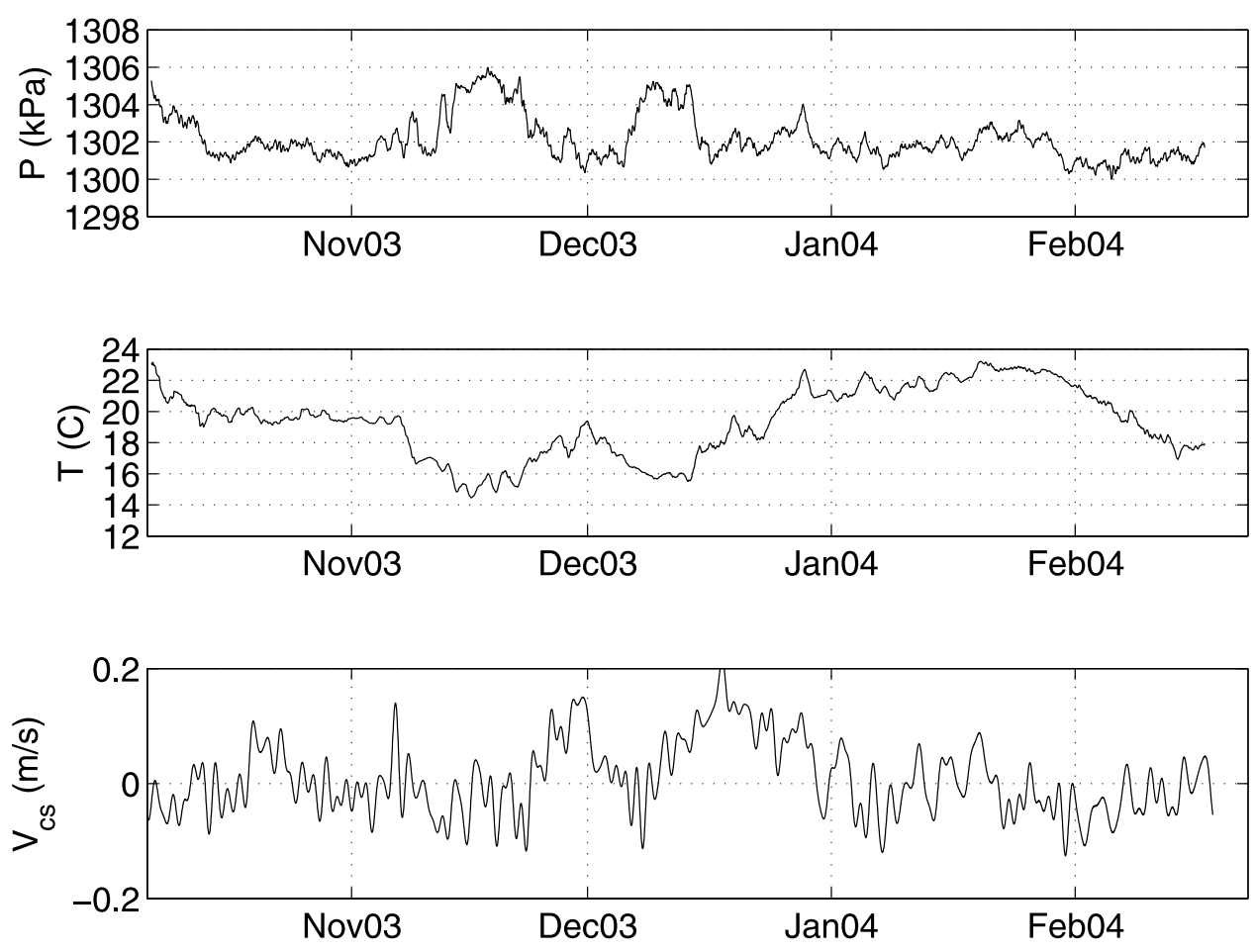

Figure 15. Daily moving averages of the (top) pressure and (middle) temperature evolutions at $130 \mathrm{~m}$ and (bottom) cross-shore velocity at $115 \mathrm{~m}$ at the M2 mooring.

the sea surface height ( $\mathrm{SSH})$ increase and the temperature drop recorded in November at the M2 mooring (Figure 15). Note that the SSH increase is inferred from the pressure increase recorded in Figure 15 and that it can't be ascribed to the M2 mooring incline under the action of current since this incline (and therefore the pressure values) would have been at its maximum around mid-December.

[35] In short, from mid-October to late November, the M2 mooring was located in a region of flow submitted to the inherent instability of the retroflection and from early November, to antagonist shoreward and seaward currents. This can explain the weak and alternating currents recorded during this period.

[36] In late November, the M2 mooring is located on the retroflection front (see Figure 8c) which infers a radical change in the current pattern: current at M2 orients northward as long as M2 is located on the NBC retroflection front and then stabilizes several days later in a northwest direction when the retroflection front has passed the M2 mooring longitude (see Figure 8d).

[37] It has already been notified in section 3 that during the second period of the survey, current velocities start to decrease at the three moorings around mid-December, pass through a minimum in early February and increase again a few days later. During this period, MODIS satellite images exhibited two contrasted situations: during the week ending February the first, the retroflection front is a long distance northwest of the moorings location (around $9-10^{\circ} \mathrm{N}$ ) but it is noticeable that the two sides of the NBC retroflection loop are about to merge together to form a retroflection eddy near the moorings location (see Figure 8e). Two weeks later (see Figure 8f), the retroflection front has reformed farther south while the freshly shed NBC ring has began its northwestward translation. The velocity decrease which started in December and continued until the beginning of February can then be related to the formation of such an eddy. As a matter of fact, during the bringing closer of the two NBC retroflection branches (one of which is feeded by the NBC while the second feeds the NECC), antagonist currents are converging and we can presume that this will decrease the NBC flow. Moreover, when the eddy has been shed, the retroflection reforms farther south, and in the present situation, the new NBC retroflection is still located northwest of our moorings (see Figure $8 \mathrm{f}$ ). For this reason, the northwestward current increases again once the NBC ring has been shed.

[38] Another illustration of cross-shelf interactions off French Guiana is given by the shelf excursion of the NBC which is suggested by several events.

[39] 1. First, the presence of the NBC is clearly indicated in the strong, directionally stable northwestward currents recorded not only at the M2 mooring which is near the shelf slope, but at the two shallower moorings.

[40] 2. Second, the velocity minimum in early February which has been ascribed to the merging of the two branches of the retroflection (see above) is reached simultaneously at the three moorings (see Figures 3 and 4). This means that at this time, the flow at the three moorings is mainly forced by a single upstream flow as part of the NBC.

[41] 3. Third, the temperature drop at the M2 mooring (at $130 \mathrm{~m}$ depth) around 6 December (Figure 15) occurs a few hours before its occurrence at the M1 and M3 moorings and 

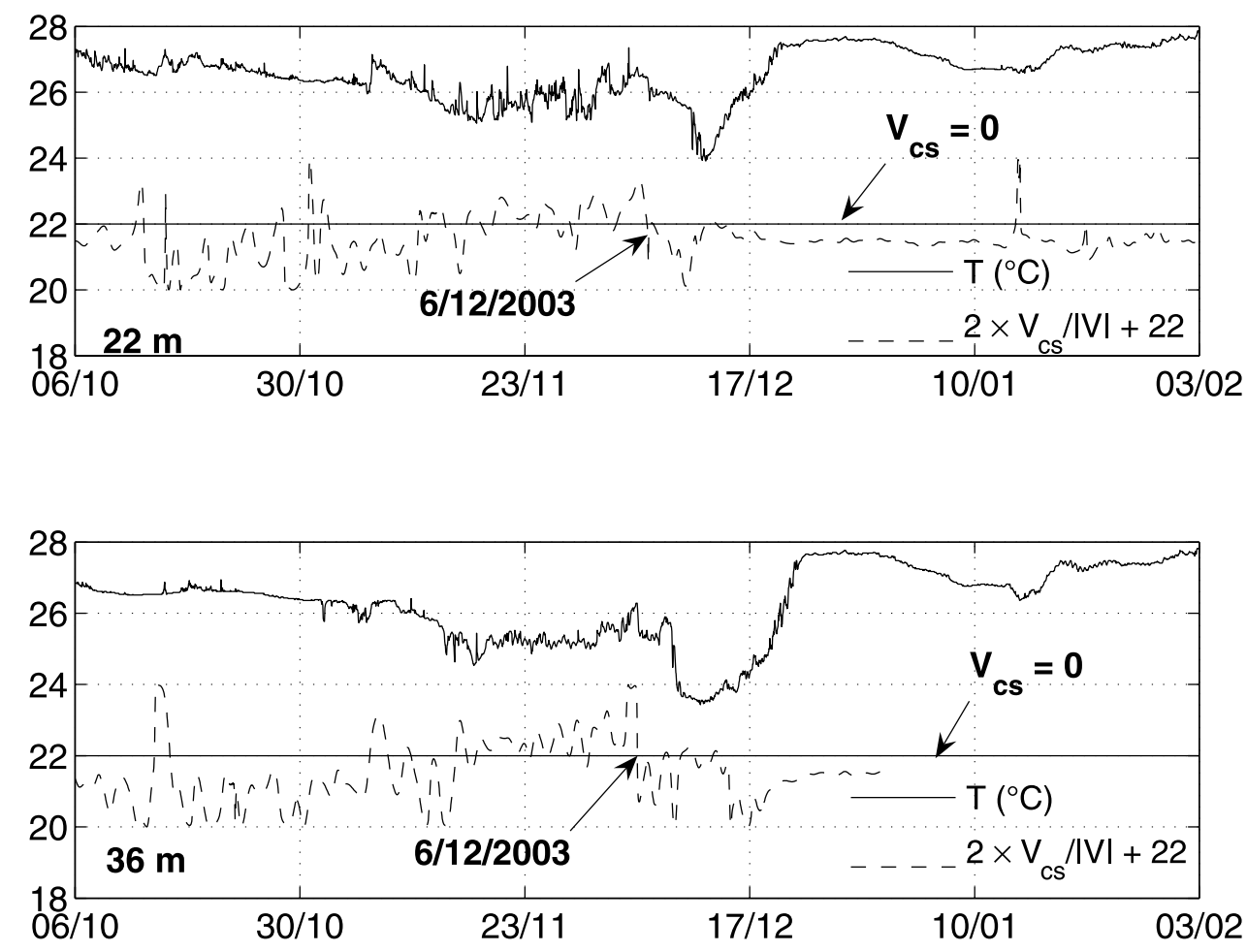

Figure 16. Temperature (T) and cross-shore normalized velocity $\left(\mathrm{V}_{c s}\right)$ at (top) $22 \mathrm{~m}$ and (bottom) $36 \mathrm{~m}$ at the M3 mooring.

is accompanied by negative (i.e., coastward) cross-shore velocities at $115 \mathrm{~m}$ and by a pressure increase. The temperature drop and pressure increase can therefore be associated to the SSH elevation occasioned by the barotropic coastward flow. In the same way, the sharp temperature drop at the M3 mooring near 6 December (see Figure 9) just precedes the setting up of the northwestward current and is likely indicative of the shoreward barotropic flow which corresponds to the NBC intrusion over the continental shelf. This is better illustrated in Figure 16 in which the superposition of temperature and cross-shore velocity evolutions at the M3 mooring show that temperature decrease begins just after the setting up of a shoreward barotropic current around 6 December evidenced at both 22 and $36 \mathrm{~m}$ depths. Hence, following that reasoning, we propose the following scenario: first, the NBC excursion on the inner shelf has advected oceanic waters, which are comparatively colder and less salty because of their proximity with the Amazon plume, from the shelf slope to the M3 mooring. Second, the Amazon plume arrives at the M3 location once a part of the NBC flow has established over the inner shelf. This is illustrated in Figure 9 by the sharp salinity decrease and temperature increase after 23 December.

[42] 4. Finally, the NBC excursion over the shelf has already been mentioned by Schott et al. [1998]. In addition, during the AMASSEDS survey, the stronger flow events in the NBC penetrated over the shelf and at least a portion of the shelf current and transport variability was driven by offshore variations in the NBC [Johns et al., 1998]. Further investigation is however necessary to determine the reasons and the frequency of such NBC excursions over the inner shelf.
[43] To investigate propagation of the NBC over the shelf, the cross-correlation function between velocity records has been calculated over the 19 November to 30 December period of time. The latter encompasses transition between the two periods of the survey and stops with the M3 lowest current meter (9098) record. The maximum cross-correlation and the corresponding lags are reported in Table 3.

[44] The values highlight the effective correlation between velocity flow at the three moorings during this period of time. Furthermore, it is noticeable that the propagation of the NBC proceeds from the open sea to the coast, from East to West and from the upper water layers to the bottom (see also Figure 4). At near $25 \mathrm{~m}$ of depth, the setting up of the NBC propagates from the M2 mooring to the shelf with a velocity of around $0.2 \mathrm{~m} / \mathrm{s}$. The direction and the plane of this propagation have been calculated thanks to the time

Table 3. Maximum Correlations Between the Detrended LowPass-Filtered Current Module Time Series in the Record Range 1300-2050 Hours From 29 November to 30 December $2003^{\text {a }}$

\begin{tabular}{lccc}
\hline Time Series $i$ & Time Series $j$ & $\begin{array}{c}\text { Maximum } \\
\text { Correlation }\end{array}$ & Lag, hours \\
\hline M3 ${ }_{\text {top }}(22 \mathrm{~m})$ & M1 $_{\text {top }}(26 \mathrm{~m})$ & 0.77 & -5 \\
$\mathrm{M} 3_{\text {top }}(22 \mathrm{~m})$ & ADCP $(25 \mathrm{~m})$ & 0.77 & 107 \\
1 $_{\text {top }}(26 \mathrm{~m})$ & ADCP $(25 \mathrm{~m})$ & 0.74 & 112 \\
$\mathrm{M} 3_{\text {bot }}(36 \mathrm{~m})$ & ADCP $(35 \mathrm{~m})$ & 0.63 & 93 \\
$\mathrm{M}_{\text {bot }}(58 \mathrm{~m})$ & ADCP $(55 \mathrm{~m})$ & 0.70 & 184 \\
\hline
\end{tabular}

${ }^{\text {a }}$ This range encompasses the transition between both periods and stops with the M3 lowest current meter (9098) record length. Positive lags imply the time series $j$ leads. 


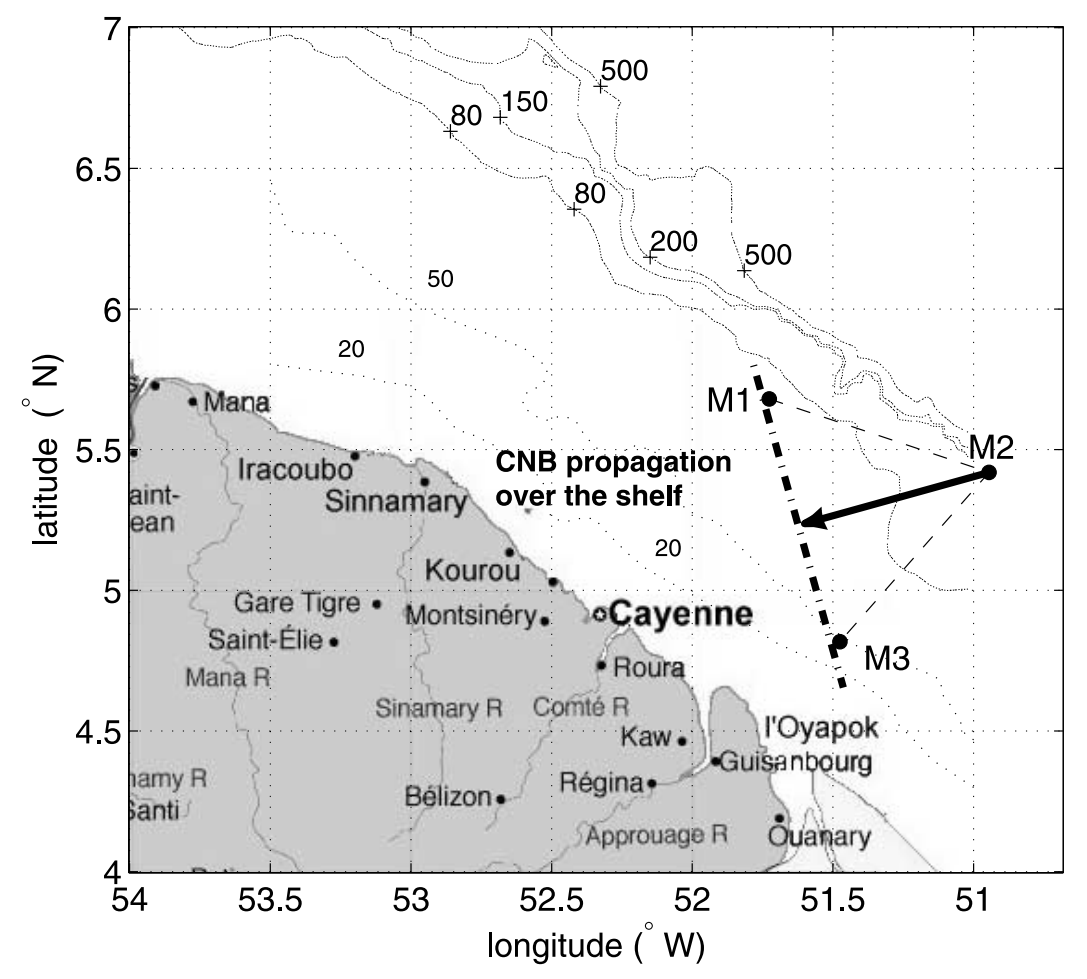

Figure 17. Propagation of the northwestward current over the shelf. The thick black arrow represents the direction of propagation, while the thick dashed line stands for the plane of propagation.

lags delivered in Table 3 and the (M2-M1) and (M2-M3) mooring distances and are represented in Figure 17.

[45] The shelf contribution (between the 50 and $150 \mathrm{~m}$ isobaths) to the NBC transport during the week 1926 December has been estimated from the weekly averaged longshore velocities on the Oyapock transect. At the M2 mooring, the velocity has been vertically integrated from surface to bottom (the measured profile from a $13 \mathrm{~m}$ to a $118 \mathrm{~m}$ depth has been linearly extrapolated to the surface and to the bottom prior to the integration). For the M3 mooring, it has been assumed that the velocity at a $22 \mathrm{~m}$ depth roughly corresponds to the vertically averaged velocity over the water column. In order to take into account bathymetric variations, vertically averaged velocities have been linearly interpolated between the latter velocities calculated at the M3 and M2 moorings. The resulting $\mathrm{NBC}$ transport over the shelf equals $4.4 \pm 0.2 \mathrm{~Sv}$ $\left(1 \mathrm{~Sv}=10^{-6} \mathrm{~m}^{3} \mathrm{~s}^{-1}\right)$ which is in accordance with previous estimations (B. Bourlès et al., personal communication, 1998) and not negligible in comparison with the NBC outer shelf transport (mean value of $16 \pm 2 \mathrm{~Sv}$ of Garzoli et al. [2004]). This result clearly questions the presumption that the NBC is an outer shelf feature. Moreover, the present study also shows that ocean color images do not precisely delineate the nearshore sides of the NBC and NBC retroflection front (as drawn in Figure 8) since they suggest that those features are outer shelf features.

[46] During the survey period, there is no sign of the continuous coastal northwestward current throughout the year often mentioned in literature [Richardson and Walsh, 1986; Johns et al., 2002; Lumpkin and Garzoli, 2005]. This can be due to the fact that this current is confined to the upper layers of the flow (in the upper $20 \mathrm{~m}$ ) and therefore inaccessible to direct measurement by our moorings. Another possible interpretation supports the theory that the whole NBC retroflects and the northwestward translation of the retroflection eddies have caused the appearance of a continuous current in the mean vectors downstream of the NBC retroflection [Richardson et al., 1994]. It can also be hypothesized that the aforementioned compensation flow observed at the M1 mooring in November actually divides near the coast and that the remnant part could be deviated northwestward and punctually feed the Guyana current as this can be seen on the velocity measurements presented by Wilson et al. [1994]. Further surface current measurements are however still necessary to close up this discussion.

[47] If we refer to previous studies [Colin et al., 1994; Johns et al., 1998], several velocity time series obtained in the western equatorial Atlantic exhibit low-frequency fluctuations dominated by a 50-70 day period oscillation which persists throughout the two consecutive years of the mooring survey presented by Colin et al. [1994]. The latter authors established that these oscillations could not be related to the 40-60 day variability found in the tropical atmosphere. Johns et al. [1990] suggested that they could be linked to the eddy formation occurring at the NBC retroflection front. As a matter of fact, it is established that 5 to 8 eddies per year are shed which roughly corresponds to a 50-70 day period phenomenon. Our velocity records are obviously too short to provide a thorough analysis of these low-frequency events. However, following the Johns et al. [1990] theory, we suggest that each eddy generation punc- 
tually decreases the NBC flow at longitudes upstream of the NBC retroflection as observed in early February in this survey, while downstream of the NBC retroflection, the 5070 day period is also characteristic through the frequency of the presence of a ring in the surroundings.

[48] As far as the Amazon plume is concerned, a recent modeling work suggests that the sharp northwestward deflection of the Amazon discharge is mainly due to the NBC [Nikiema et al., 2007]. Moreover, the presence of the plume over the French Guiana continental shelf is clearly conditioned by the position of the NBC retroflection front: when the latter is southward of the French Guiana coast, the plume is rerouted eastward and only the southeastern part of the continental shelf can be impacted by Amazon river waters. This situation has been encountered at the beginning of the survey in which salinity records at the M1 and M3 moorings are clearly indicative of the presence of marine water at a $22 \mathrm{~m}$ depth and beyond (see Figures 9 and 10). By contrast, once the NBC retroflection front has translated northwestward, the plume becomes confined to the continental shelf off the French Guiana coasts and is rerouted eastward at higher latitudes. This situation is observed from 23 December when sharp salinity decrease starts at both of the shallowest moorings. During this period, salinity values are clearly lower at $\mathrm{M} 3(22 \mathrm{~m})$ than at $\mathrm{M} 1(26 \mathrm{~m})$ which means that the core of the plume is confined to the nearshore region, shoreward of M1 (this is also evidenced in the MODIS satellite images in Figure 8d). In the latter situation, freshwater signals are detected down to $36 \mathrm{~m}$ depth at the location of the M3 mooring. This corroborates previous measurements obtained as part of the WOCE experiment in which freshwater signals were observed down to about $50 \mathrm{~m}$ depth.

[49] NBC rings also impact distribution of the Amazon plume waters. They contribute to the dispersal of fresh and nutrient-rich waters and their northwestward transport toward the Caribbean Sea. Moreover, since NBC rings undergo shape deformation (see Figure 8), it is difficult to determine the eventual fate of the core water transported within these rings.

\section{Conclusion}

[50] The present mooring survey along with satellite images covering the survey period have provided new insights into marine circulation over the French Guiana continental shelf. Two contrasted situations that are governed by the location of the NBC retroflection front have been evidenced. The first situation is observed at the beginning of the survey and corresponds to a NBC retroflection front located southeast of the moorings while an NBC ring is located to the northwest. Such a configuration brings weak currents (mean velocities near a $25 \mathrm{~m}$ depth comprising between 0.17 and $0.3 \mathrm{~m} / \mathrm{s}$ ) with fluctuating directions. Moreover, velocity, temperature and SSH records suggest that, just downstream of the retroflection front, a shoreward flow establishes to compensate the seaward advection of waters by the NBC retroflection.

[51] The second characteristic situation corresponds to a NBC retroflection front located northwest of the moorings (as observed from mid-December) which brings a drastically different current pattern due to the likely NBC excursion over the inner shelf. The resulting currents are strong (up to $1.5 \mathrm{~m} / \mathrm{s}$, with mean velocities near a $25 \mathrm{~m}$ depth comprising between 0.37 and $1.14 \mathrm{~m} / \mathrm{s}$, respectively, at the shallowest and the deepest moorings) and stabilized in the northwest direction. It has also been suggested in this study that the current velocities can temporarily decrease (as observed in early February) because of the bringing closer of the two branches of the NBC retroflection and the subsequent formation of a retroflection ring. Afterward, current velocities increase again once the ring has been shed provided the new retroflection front is still located northwest of the mooring.

[52] An important result concerns the Guyana current which was thought to propagate northwestward along the coast year round even when the retroflection occurred southeastward of the French Guiana coast. Such a current was not detected off French Guiana during this 5 month survey either because it is actually confined to the upper layers of the flow (in the upper $20 \mathrm{~m}$ ) or because it does not persist all throughout the year.

[53] Moreover, it is likely that the 50-70 day period oscillations that have been reported in several previous works [e.g., Johns et al., 1990; Colin et al., 1994] correspond to the frequency of NBC ring formation (as suggested by Johns et al. [1990]). These low-frequency oscillations should therefore be observed in the current velocity data, not only downstream of the retroflection front due to ring passages, but upstream of the front through regular decreases of the velocity due to the two branches drawing closer preceding ring formation. However, our velocity records are obviously too short to give full evidence of this and further measurements are therefore still necessary.

[54] As a main result, a strong correlation has been established between mesoscale features occurring outer shelf and the inner shelf flow pattern. Some of these features are not only felt near the shelf slope (at the M1 and M2 moorings) but about $100 \mathrm{~km}$ shoreward at the shallowest mooring M3, which questions the presumption that the $\mathrm{NBC}$ and rings are off-shelf features. As a matter of fact, it has been evidenced (see section 5) that when the NBC retroflection occurs northwest of the French Guiana continental shelf, part of the NBC climbs over the shelf slope and propagates to the inner shelf in the cross-shore direction with a velocity of $0.2 \mathrm{~m} / \mathrm{s}$. In addition, the shelf contribution to NBC transport during the week 19-26 December has been estimated to $4.4 \pm 0.2 \mathrm{~Sv}$. Finally, around $30 \%$ of the surface of the NBC ring detected in early October 2003 was over the continental shelf (shoreward of the $200 \mathrm{~m}$ isobath) though the mean trajectory traced by NBC ring centers is offshore the $500 \mathrm{~m}$ isobath [Goni and Johns, 2001] in water $3000-4000 \mathrm{~m}$ deep according to Fratantoni and Glickson [2002].

[55] The location of the NBC retroflection has also a strong impact on the presence of the Amazon plume over the French Guiana continental shelf. When the NBC retroflection is located southward of the $4^{\circ} \mathrm{N}$ latitude, the spreading of the Amazon plume is reduced and confined to the southeastern corner of the shelf or even nonexistent. This horizontal spreading increases with the northwestward displacement of the NBC retroflection beyond the $4^{\circ} \mathrm{N}$ latitude and it is accompanied by a vertical spreading of 
freshwater down to about a $40 \mathrm{~m}$ depth. Hence the strong year-to-year variability in location of the NBC retroflection [Fonseca et al., 2004] suggests that the nutrient and biomass enrichment of the French Guiana continental shelf by the Amazon plume is also submitted to strong year-toyear variations. One can therefore presume that this will have large consequences over the whole trophic web in this region.

[56] Finally, though this survey was restricted to five months, it can also be helpful in our understanding of the remaining year. Hence, when retroflection takes place, the presence or not of a coastal northwestward current along the South American coast above $4^{\circ} \mathrm{N}$ will be governed by the position of the retroflection front. The latter is not only submitted to the annual migration of the ITCZ [Fonseca et al., 2004], but to the frequency of NBC ring generation since the shedding of a ring induces a reformation southward of the retroflection front. In this context, it is likely that all throughout the year, periods of weak and variable currents (possibly influenced by the presence of an NBC ring) will alternate with periods of strong and stable northwestward currents when the NBC reaches the continental shelf.

[57] Acknowledgments. This work has been supported by the French Research and Development Institute (IRD), the French National Program on Coastal Environment (PNEC), the French Institute for Sciences of the Universe (INSU), and the Oceanological Institute in Marseille (COM). The authors are grateful to the crew of the Hermano Gines vessel and to their colleagues from IRD, Fundacion La Salle de Sciencias Naturales (FLASA), and the ELICO laboratory (UMR CNRS 8013) who contributed to the preparation, realization, and analysis of the measurements. We are also grateful to Claudie Marec for her willingness and her skilled assistance during the mooring operation, to A. Sournia and to G. Reverdin for their support, and to B. Bourlès, who agreed to retrieve our moorings during the PIRATA cruise

\section{References}

Barnier, B., T. Reynaud, A. Beckmann, C. Böning, J. M. Molines, S. Barnard, and Y. Jia (2001), On the seasonal variability and eddies in the North Brazil Current: Insights from model intercomparison experiments, Prog. Oceanogr., 48, 195-230.

Bendat, J. S., and A. G. Piersol (2000), Random Data Analysis and Measurement Procedures, Wiley-Interscience, New York.

Bourlès, B., Y. Gouriou, and R. Chuchla (1999), On the circulation in the upper layer of the western equatorial Atlantic, J. Geophys. Res., 104, $21,151-21,170$

Bourret, A., J.-L. Devenon, and C. Chevalier (2005), Investigation on passive open boundary conditions adapted to the conjonction of strong currents, standing tidal wave and high stratification: Application to the French Guiana continental shelf, Cont. Shelf Res., 25, 13531373.

Chevalier, C., M. Baklouti, and A. Ramamonjarisoa (2004), Modeling the influence of wind and rivers on current, salinity and temperature over the French Guiana continental shelf during the rain season, J. Coastal Res., 20, $1183-1197$

Colin, C., B. Bourles, R. Chuchla, and F. Dangu (1994), Western boundary current variability off French Guiana as observed from moored current measurements, Oceanol. Acta, 17, 345-354

Didden, N., and F. Schott (1993), Eddies in the North Brazil Current retroflection region observed by Geosat altimetry, J. Geophys. Res., 98, $20,121-20,131$

Equipe Etude du Transport Atlantique Méridien dans le Bassin Ouest Équatorial (1997), Opération sabord0: Recueil de données, technical report, Inst. de Rech. pour le Dev., Cayenne, France.

Ffield, A. (2005), North Brazil current rings viewed by TRMM Microwave Imager SST and the influence of the Amazon plume, Deep Sea Res., Part I, 52, 137-160.

Flagg, C. N., R. L. Gordon, and S. Mc Dowell (1986), Hydrographic and current observations on the continental slope and shelf in the western equatorial Atlantic, J. Phys. Oceanogr., 16, 1412-1429.
Fonseca, C. A., G. J. Goni, W. E. Johns, and E. J. D. Campos (2004), Investigation of the North Brazil Current retroflection and North Equatorial Countercurrent variability, Geophys. Res. Lett., 31, L21304, doi:10.1029/2004GL020054.

Foreman, M. G. (1978), Manual for Tidal Currents Analysis and Prediction, Inst. of Ocean Sci. Patricia Bay, Sidney, B. C., Canada.

Fratantoni, D. M., and D. A. Glickson (2002), North Brazil Current ring generation and evolution observed with SeaWIFS, J. Phys. Oceanogr., $32,1058-1074$.

Fratantoni, D. M., and P. L. Richardson (2006), The evolution and demise of North Brazil Current rings, J. Phys. Oceanogr., 36, 1241-1264.

Fratantoni, D. M., W. E. Johns, and T. L. Townsend (1995), Rings of the North Brazil Current: Their structure and behavior inferred from observations and a numerical simulation, J. Geophys. Res., 100, 10,63310,654 .

Froidefond, J., S. Lavender, P. Laborde, A. Herbland, and V. Lafon (2002), SeaWIFS data interpretation in a coastal area in the Bay of Biscay, Int. J. Remote Sens., 23, 881-904.

Garzoli, S. L., A. Ffield, W. E. Johns, and Q. Yao (2004), North Brazil Current retroflection and transports, J. Geophys. Res., 109, C01013, doi:10.1029/2003JC001775.

Geyer, W. R., R. C. Beardsley, S. J. Lentz, J. Candela, R. Limeburner, W. E. Johns, B. M. Castro, and I. D. Soares (1996), Physical oceanography of the Amazon shelf, Cont. Shelf Res., 16, 575-616.

Goni, G. J., and W. E. Johns (2001), A census of North Brazil Current rings observed from T/P altimetry: 1992-1998, Geophys. Res. Lett., 28, $1-4$.

Hellweger, F. L., and A. L. Gordon (2002), Tracing Amazon river water into the Caribbean Sea, J. Mar. Res., 60, 537-549.

Hu, C., E. T. Montgomery, R. W. Schmitt, and F. Müller-Karger (2004), The dispersal of the Amazon and Orinoco water in the tropical Atlantic and Caribbean Sea: Observation from space and S-PALACE floats, Deep Sea Res., Part II, 51, 1151-1171.

Johns, W. E., T. N. Lee, F. A. Schott, R. J. Zantopp, and R. H. Evans (1990), The North Brazil Current retroflection: Seasonal structure and eddy variability, J. Geophys. Res., 95, 22,103-22,120.

Johns, W. E., T. N. Lee, R. C. Beardsley, J. Candela, R. Limeburner, and B. Castro (1998), Annual cycle and variability of the North Brazil Current, J. Phys. Oceanogr., 28, 103-128.

Johns, W. E., T. L. Townsend, D. M. Fratantoni, and W. D. Wilson (2002), On the Atlantic inflow to the Caribbean Sea, Deep Sea Res., Part I, 49, $211-243$.

Lentz, S. J. (1995), The Amazon river plume during AMASSEDS: Subtidal current variability and the importance of wind forcing, J. Geophys. Res., $100,2377-2390$.

Lentz, S. J., and R. Limeburner (1995), The Amazon river plume during AMASSEDS: Spatial characteristics and salinity variability, J. Geophys. Res., 100, 2355-2375.

Lumpkin, R., and S. L. Garzoli (2005), Near-surface circulation in the tropical Atlantic Ocean, Deep Sea Res., Part I, 52, 495-518.

Madden, R. A., and P. R. Julian (1972), Description of global scale circulation in the tropics with a 40-50 days period, J. Atmos. Sci., 29, 11091123

Müller-Karger, F. E., C. R. McClain, and P. L. Richardson (1988), The dispersal of the Amazon's water, Nature, 333, 56-59.

Nikiema, O., J. L. Devenon, and M. Baklouti (2007), Numerical modeling of the Amazon River plume, Cont. Shelf Res., in press.

Nof, D., and T. Pichevin (1996), The retroflection paradox, J. Phys. Oceanogr., 26, 2344-2358.

Pailler, K., B. Bourlès, and Y. Gouriou (1999), The barrier layer in the western tropical Atlantic Ocean, Geophys. Res. Lett., 26, 2069-2072.

Pauluhn, A., and Y. Chao (1999), Tracking eddies in the subtropical northwestern Atlantic Ocean, Phys. Chem. Earth, Part A, 24, 415-421.

Pujos, M., and J. M. Froidefond (1995), Water masses and suspended matter circulation on the French Guiana continental shelf, Cont. Shelf Res., 15, 1157-1171.

Richardson, P. L., and G. Reverdin (1987), Seasonal cycle of velocity in the Atlantic north equatorial countercurrent as measured by surface drifters, current meters, and ship drifts, J. Geophys. Res., 92, 3691-3708.

Richardson, P. L., and D. Walsh (1986), Mapping climatological seasonal variations of surface currents in the tropical Atlantic using ship drifts, J. Geophys. Res., 91, 10,537-10,550.

Richardson, P. L., G. E. Hufford, R. Limeburner, and W. S. Brown (1994), North Brazil Current retroflection eddies, J. Geophys. Res., 99, 50815093

Schott, F. A., J. Fischer, and L. Stramma (1998), Transports and pathways of the upper-layer circulation in the western tropical Atlantic, J. Phys. Oceanogr., 28, 1904-1928.

Stramma, L., and F. Schott (1999), The mean flow field of the tropical Atlantic Ocean, Deep Sea Res., Part II, 46, 279-303. 
Wilson, W. D., E. Johns, and R. L. Molinari (1994), Upper layer circulation in the western tropical North Atlantic Ocean during August 1989, J. Geophys. Res., 99, 22,513-22,523.

M. Baklouti, UMR 6535, Laboratoire d'Océanographie et de Biogéochimie, Institut de Recherche pour le Développement, Campus de Luminy, case 901, F-13288 Marseille cedex 09, France. (baklouti@com. univ-mrs.fr)
A. Bourret and J.-L. Devenon, Laboratoire d'Océanographie et de Biogéochimie, Campus de Luminy, case 901, F-13288 Marseille, France. J.-M. Froidefond, UMR 5805, DGO, Université Bordeaux I, F-33405 Talence, France.

J.-L. Fuda, Centre d'Océanologie de Marseille, F-13288, Marseille, France.

J.-F. Ternon, UR 109, Institut de Recherche pour le Développement, Centre de Recherche Halieutique Méditerranéenne et Tropicale, F-34203 Sète, France. 